\title{
VI. The absorption of the different types of beta rays, together with a study of the secondary rays excited by the them
}

\section{V.E. Pound M.A.}

To cite this article: V.E. Pound M.A. (1909) VI. The absorption of the different types of beta rays, together with a study of the secondary rays excited by the them, Philosophical Magazine Series 6, 17:97, 126-153, DOI: 10.1080/14786440108636583

To link to this article: http://dx.doi.org/10.1080/14786440108636583

曲 Published online: 21 Apr 2009.

Submit your article to this journal $₫$

Џll Article views: 2

Q View related articles $\longleftarrow$

Citing articles: 1 View citing articles 5 
VI. The Absorption of the Ilifferent Types of Beta Rays, together with a Study of the Secondary Rays excited by them. By V. E. Pound, M.A., University of Toronto*.

[Plate II.]

I. IntRoduction.

TN a paper in the Phil. Mag. of July 1907, Prof. Mac1 kenzie gives an account of some observations which he made on the secondary radiation issuing from each side of plates of lead upon which a pencil of $\beta$ rays was allowed to fall. Using plates of increasing thickness, he found that the secondary radiation issuing from the side of the plate upon which the $\beta$ rays fell, gradually increased in intensity and reached a maximum value when a plate $2 \mathrm{~mm}$. in thickness was used. With plates of still greater thickness, this secondary radiation remained constant in intensity. $\mathrm{He}$ obtained, however, an entirely different result on investigating the secondary radiation from the back of the plate upon which the $\beta$ radiation was allowed to fall. Under these conditions, the secondary radiation fell off very slowly as the thickness of the plates increased, and was still quite measurable with plates of lead $15 \mathrm{mms}$. in thickness.

In arriving at these results Mackenzie $\dagger$ investigated the secondary radiation issuing from each side of the plates, first, when both $\beta$ and $\gamma$ rays were allowed to fall on them, and, second, when $\gamma$ rays alone were allowed to fall on the plates; and the results quoted by him, and ascribed by him to the action of the $\beta$ rays, were obtained by subtracting the effects due to the $\gamma$ rays alone from those due to the combined $\beta$ and $\gamma$ radiations.

With the arrangement he adopted, it was possible that in cutting off the $\beta$ rays in order to study the effect of the $\gamma$ radiation alone, he also cut off a greater proportion of the latter than he estimated. If this were so, it would result in ascribing to the $\beta$ radiation a part of the secondary radiation which properly should have been ascribed to the $\gamma$ rays.

In view of the importance of his results in their relation to theories of secondary radiation now being put forward by Bragg + and others, it was thought well to make a joore extended examination of the secondary radiations excited by both $\beta$ and by $\gamma$ rays; and in the following paper an account

* Communicated by Prof. J. C. McLennan. Read before the Royal Society of Canada, May 16, 1908.

+ Phil. Mag. July 1907.

千 Phil. Mag. May 1908. 
is given of some experiments in which the secondary radiation both from the back and front of metal plates was studied when these were traversed by $\gamma$ rays alone, and also when pencils of $\beta$ rays of different types were allowed to fall on them.

In differentiating the effects due to the various types of rays, the action of each was ascertained by deflecting pencils of each type into an ionization-chamber a way from the others by means of a magnetic field.

\section{Apparatus.}

The arrangement adopted is shown in fig. 1 . The receptacle for holding the radium was a lead cylinder $\mathrm{A}$ with walls $4 \mathrm{cms}$. thick. One end of the cylinder was covered by

Fig. 1.

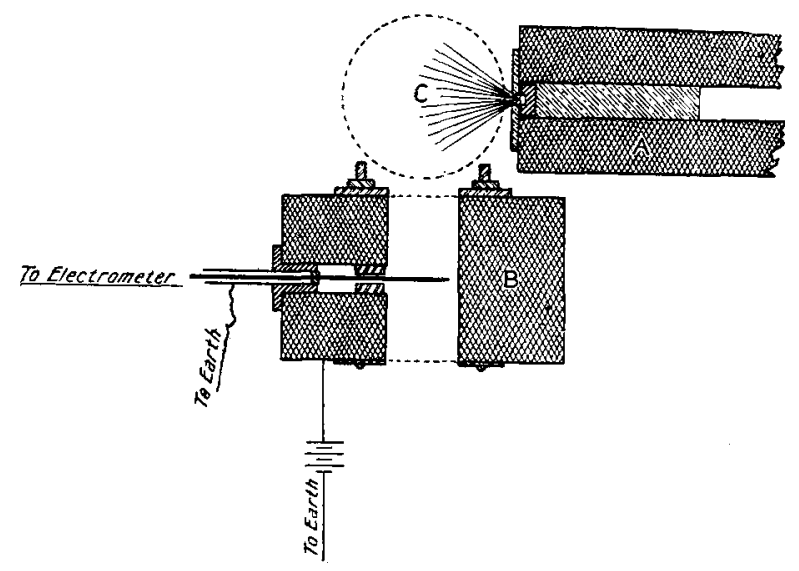

a brass plate $2.5 \mathrm{mms}$." thick, in the centre of which was a hole $4.5 \mathrm{mms}$. in diameter. The capsule holding the radium was held close against this plate in such a position that the rays from the radium on issuing, passed between the poles of a powerful electromagnet. Immediately beneath the pole-pieces of the electromagnet was the ionizationchamber B. It also was made of lead in the form of a cylinder $6.7 \mathrm{cms}$. long, with walls $4 \cdot 6 \mathrm{cms}$. in thickness, the ionization-chamber proper being $4.7 \mathrm{cms}$. in diameter. At the top and bottom were brass rings to hold different thicknesses of selected absorbing materials over the ends of the chamber.

A properly screened and insulated electrode was inserted 
into the ionizing-chamber and connected to a Dolezalek electrometer by means of which saturation currents were measured. The sensibility of the electronneter was such that a potential-difference of one rolt between the quadrants produced a deflexion of $625 \mathrm{mms}$. on a scale abont one metre distant from the needle. It was found that a potential of 240 volts applied to the jonization-chamber was ulways amply sufficient to give the saturation current.

\section{Expertments on the Absorption and Reflexion of $\beta$ Rays by TinforL.}

\section{A. Measurements on Transmitted Rays.}

In these experiments the $\beta$ rays from the radium, on coming between the poles of the magnet, were deflected either downwards or upwards according to the direction of the field between the poles. As the capsule containing the radium was covered by a thin sheet of mica the $\alpha$ rays were largely absorbed, so that the issuing beam contained only $\beta$ and $\gamma$ rays, which could easily be separated by the magnetic field in the manner indicated. Readings were taken of the saturation currents in the ionization-chamber as the current through the electromagnet was changed by small increments from 0 to about 28 amperes.

A series of measurements was made with a number of different thicknesses of absorbing layers of tinfoil over the top of the ionization-chamber, and with the bottom of the chamber closed by a thin sheet of aluminium-foil $0.0065 \mathrm{~mm}$. in thickness.

Belore making these, however, a set of readings was taken without any metallic covering over the opening at the top of the ionizing-chamber, and with only the single sheet of aluminium-foil over the opening at the bottom. In taking these the magnetic field was first applied in such a direction as to deflect the $\beta$ rays down into the chamber, and observations were made on the saturation currents corresponding to various field-strengths. The field was then reversed, and a second set of readings taken as the $\beta$ rays were gradually deflected upwards and away from the chamber. Both set, of readings are given in column I. of Tables I. and II. respectively, and curves representing them are shown in fig. 2 (Pl. II.). From these curves it is seen that as the $\beta$ rays were deflected down into the chamber by the magnetic field, the ionization in the chamber rapidly increased to a maximum value, and then decreased as the different pencils of rays were swept past by the increasing magnetic fields. It is seen, 
Different Types of Beta Rays.

TABLE I. - Ionization by $\beta$ transmitted Secondary Rays from Tinfoil with Primary Rays reflected down into Chamber.

\begin{tabular}{|c|c|c|c|c|c|c|c|c|}
\hline \multirow{2}{*}{$\begin{array}{l}\text { Current } \\
\text { in magnet } \\
\text { (amperes). }\end{array}$} & \multicolumn{8}{|c|}{$\begin{array}{c}\text { Saturation Currents (urbitrary seale) with different } \\
\text { thicknesses of Tinfoil. }\end{array}$} \\
\hline & $\begin{array}{c}1 . \\
\min . \\
0 \cdot 00\end{array}$ & $\begin{array}{c}\text { IJ. } \\
\text { min. } \\
0 \cdot 0196\end{array}$ & $\begin{array}{c}\text { III. } \\
\text { mm. } \\
0 \cdot 0784\end{array}$ & $\begin{array}{c}\text { IV. } \\
\text { mim. } \\
0 \cdot 1568\end{array}$ & $\begin{array}{c}\nabla . \\
\text { nm. } \\
0.3136\end{array}$ & $\begin{array}{l}\text { VI, } \\
\text { mm. } \\
1.254\end{array}$ & $\begin{array}{l}\text { VII. } \\
\mathrm{mm} . \\
1.96\end{array}$ & $\begin{array}{l}\text { VIII. } \\
\text { min. } \\
3: 136\end{array}$ \\
\hline 0.0 & $46 \cdot 6$ & $42 \cdot 3$ & $27 \cdot 3$ & $23 \cdot 3$ & $19 \cdot 4$ & 16.25 & $14 \cdot 59$ & $13 \cdot 08$ \\
\hline & & & & & & स & $1+00$ & 1000 \\
\hline 0.45 & 1284 & $84 \%$ & & & & & & \\
\hline 0.85 & $292 \div 0$ & $196 \cdot 5$ & $52 \cdot 0$ & $27^{\circ} 0$ & $20 \cdot 3$ & $\ldots$ & $14: 51$ & $12 \cdot 87$ \\
\hline & 348.5 & & 860 & & & & & \\
\hline 165 & $360^{\circ} 0$ & $343 \cdot 2$ & 1520 & $62 \cdot 6$ & 250 & & $\cdots$ & 1273 \\
\hline 39 & & $327 \cdot 3$ & $221 \cdot 1$ & 115 & & $16 \cdot 19$ & & \\
\hline 25 & 3050 & $\cdots$ & & & 45.8 & $16 \cdot 19$ & & 1266 \\
\hline $3 \cdot 2$ & 1702 & & $161 \cdot 9$ & & & & $14 \cdot 44$ & \\
\hline 4.0 & $\ldots$ & 1493 & & $97 \cdot 4$ & 628 & $16 \cdot 13$ & & 1261 \\
\hline $5 \cdot($ & $\ldots$ & & $96 \cdot 9$ & $79 \cdot 0$ & 570 & $16 \cdot 48$ & $14 \cdot 35$ & $12 \cdot 45$ \\
\hline $6 \cdot 6$ & & $81 \cdot 1$ & $6 \cdot \cdot 1$ & & 467 & & $14 \cdot 21$ & \\
\hline 7 & 625 & $73 \cdot 4$ & $\cdots$ & 58.5 & & 16.43 & & $12 \cdot 29$ \\
\hline 100 & 34.0 & $50 \cdot 7$ & $47 \cdot 1$ & $45 \cdot 2$ & 345 & 16 & 14 & $12 \cdot 28$ \\
\hline & 208 & 354 & 29.8 & $31 \cdot 5$ & $25 \cdot 7$ & 15 & 13.96 & $12 \cdot 22$ \\
\hline $20^{\circ}$ & $16 \cdot 0$ & 27.5 & $26 \cdot 5$ & $25 \cdot 4$ & 22.5 & $15 \cdot 64$ & 1385 & \\
\hline & $\ldots$ & & & & 20.0 & 1551 & 13.82 & \\
\hline $27 \cdot 5$ & $\ldots$ & 230 & $22 \cdot 2$ & 220 & $\cdots$ & $\ldots$ & $\ldots$ & $12 \cdot 1$ \\
\hline
\end{tabular}

TABLE II.-Ionization by $\beta$ transmitted Seconday Rays from 'linfoil with Primary Rays deflected up from Chamber.

\begin{tabular}{|c|c|c|c|c|c|c|c|c|}
\hline \multirow{2}{*}{$\begin{array}{l}\text { Current } \\
\text { in magnet. }\end{array}$} & \multicolumn{8}{|c|}{$\begin{array}{l}\text { Saturation Current (arbitrary scale) for different } \\
\text { thicknesses of Tinfoil. }\end{array}$} \\
\hline & $\underset{0 .}{I}$ & $\begin{array}{c}\text { II } \\
\text { mins. } \\
0.0196\end{array}$ & $\underset{\substack{\text { III } \\
\text { mmic } \\
0.0784}}{\text {, }}$ & $\begin{array}{c}\mathrm{IV} . \\
\mathrm{mm} . \\
0 \cdot 1568\end{array}$ & $\begin{array}{c}\mathrm{V} . \\
\text { Inm. } \\
0-3136\end{array}$ & $\begin{array}{c}\text { VI. } \\
\text { mm. } \\
1 \cdot 254\end{array}$ & $\begin{array}{l}\text { VII. } \\
\text { ImIm. } \\
1.96\end{array}$ & $\begin{array}{l}\text { VIIII } \\
\text { mim. } \\
3 \cdot 130\end{array}$ \\
\hline 0.0 & $46 \cdot 6$ & 41.7 & $26 \cdot 4$ & $22 \cdot 1$ & $19 \cdot 1$ & 16.25 & 14.55 & 1282 \\
\hline $\begin{array}{l}07 \\
085\end{array}$ & 147 & $23 \cdot 2$ & $20 \cdot 9$ & $20 \cdot 1$ & $18 \cdot 3$ & $\ldots$ & $14 \cdot 34$ & \\
\hline $\begin{array}{l}1.45 \\
1.70\end{array}$ & 10.5 & & 195 & 790 & $18 \cdot 0$ & & - & 10.50 \\
\hline $1 \cdot 30$ & $\ldots$ & 184 & $\ldots$ & & & 1584 & $\cdots$ & 12.56 \\
\hline 2.5 & 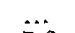 & & & & 178 & 1584 & $\ldots$ & 12.52 \\
\hline 38 & $7 \cdot 6$ & 17.3 & 17.9 & $18 \cdot 2$ & $17-7$ & 1573 & ... & $12 \cdot 44$ \\
\hline $5 \cdot 0$ & & $\ldots$ & 178 & $17 \cdot 9$ & $17 \%$ & $15-68$ & & $12-4$ \\
\hline $\begin{array}{l}6 \cdot 6 \\
70\end{array}$ & $\begin{array}{l}7-41 \\
\ldots\end{array}$ & 169 & $17 \cdot 5$ & $17 \cdot 8$ & $17 \cdot 3$ & 15.58 & $14 \cdot 15$ & $\mathrm{~L} 2 \cdot 36$ \\
\hline 100 & $\ldots$ & 168 & & & 172 & $15 \cdot 21$ & 14.09 & 1226 \\
\hline $12 \cdot 0$ & & & $17 \cdot 9$ & $17 \cdot 6$ & & & & \\
\hline $\begin{array}{l}15 \circ 0 \\
17.5\end{array}$ & $7 \cdot 23$ & 166 & 179 & 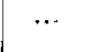 & $17 \cdot 0$ & 15.29 & 139 & $12 \cdot 10$ \\
\hline 210 & $7 \cdot 11$ & $16 \cdot 3$ & & $17 \cdot 3$ & 169 & $15 \cdot 17$ & 1387 & 12.06 \\
\hline 265 & $\ldots$ & $16^{\circ} 2$ & 176 & $17 \cdot 2$ & 168 & $\ldots$ & 1379 & \\
\hline
\end{tabular}

Phil. Mag. S. 6. Vol. 17. No. 97. .Tan. 1909. 
also, that when the $\beta$ rays were deflected upwards and away from the chamber by gradually increasing magnetic fields, the corresponding saturation currents decreased rapidly until a constant limiting value was reached.

As already stated, similar sets of readings were taken for different thicknesses of absorbing layers of tinfoil over the top of the chamber. In columns II., III., IV., and V. of Table I. are given the results obtained with layers $0.0196 \mathrm{~mm}$., $0.0784 \mathrm{~mm}$., $0.1568 \mathrm{~mm}$, and $0.3136 \mathrm{~mm}$. in thickness respectively, and curves $A, B, C$, and $D$, corresponding to the results given in these columns, are shown in fig. 3 (Pl. II.).

Here again, it will be seen, when the $\beta$ rays were deflected downwards, that with each absorbing layer the saturation current passed through a masimum value. It will be seen, too, that the maximum saturation current fell away as the absorbing layer was increased, and further, that as the thickness of the layers was increased it required a stronger and stronger field to produce the maximum ionization.

The explanation of these results is found in the fact that the $\beta$ rays issued from the radium in a number of approximately homogeneous sheaves or pencils possessing a maximum intensity in a direction at right angles to the axis of the ionizing-chamber. On applying the magnetic fields, these sheaves or pencils would undergo different degrees of deflexion, those of high velocity being less affected by the field than the more slowly moving ones.

As the rays from a sheaf of low velocity would enter the chamber first, the ionization would increase and reach a maximum when the axis of this sheaf of rays coincided with the axis of the ionizing-chamber. Still higher fields would deflect the slow moving rays past the opening of the ionizingchamber and introduce others possessing still higher velocities. Inasmuch as Bragg* and others have shown that the ionizing power of $\beta$ rays of high velocity is not so great as that of those moving more slowly, it follows that with increasing magnetic fields the ionizing power of the rays introduced would be less than that of the rays cut out, and hence a drop in the ionization values would occur. This drop in the conductivity would continue until ultimately all the deflectable $\beta$ rays were swept past tho chamber. As the layers of tinfoil were gradually increased in thickness, the more slowly moving $\beta$ rays would be absorbed, and the first effective sheaves transmitted would consist of rays possessing bigher and higher penetrability, and consequently of rays with less and less ionizing power. It follows, then, that while a maximum

* Bragg, Phil. Mag. Oct. 1907. 
conductivity would be obtained with each thickness of tinfoil, the value of the maximum would decrease with the thickness of the absorbing layer. It is evident, too, since with increasing thicknesses the first effective sheaves of transmitted rays would possess higher and higher velocities, that the field required to deflect the axes of these different sheaves into coincidence with the axis of the chamber would increase. Hence the maximum conductivities, when absorbing. layers of increasing thicknesses were used, would be obtained. by fields excited by currents of greater and greater intensity, and this, as the curves $A, B, C$, and D show, is actually what happened.

The numbers corresponding to the saturation currents: obtained with different absorbing layers when the rays were deflected upwards and away from the chamber by the magnetic fields, are given in columns II., III., IV., and V. of Table II., and curves representing them are shown in fig. 4 . From these it will be seen that with each absorbing layer the ionization fell away as the rays were deflected upwards, and soon reached a value which was constant, and which represented the natural conductivity of the air in the chamber, together wilh that impressed upon it by the undeviable rays from the radium and by the secondary rays which they excited.

These limiting curves, it will be seen, exhibit an effect already pointed out and emphasized by Mackenzie * and others, that when the thickness of a plate or wall upon which $\gamma$ rays are allowed to fall is gradually increased, the gain in ionization at the back of the plate from the secondary radiation is at first greater than the loss produced by the absorption of the primary rays. This result is well exemplified by the curves $A^{\prime}, B^{\prime}, C^{\prime}$, and $D^{\prime}$, which correspond to absorbing layers of increasing thicknesses, and which show that the limiting value of the ordinate of $\mathrm{B}^{\prime}$ is greater than that of $\mathrm{A}^{\prime}$, that of $\mathrm{C}^{\prime}$ is equal to that of $\mathrm{B}^{\prime}$, and that of $\mathrm{D}^{\prime}$ is again less than that of $\mathrm{C}^{\prime}$.

In addition to the measurements just described, others were taken for magnetic fields in both directions with absorbing layers $1.254 \mathrm{mms}$, $1.96 \mathrm{mms}$, and $3.136 \mathrm{mms}$. in thickness, and the results of these are recorded in columns VI., VII., and VIII. of Table I. The curves E, F, and G, fig. 5, were plotted from the numbers in these columns, and represent the conductivities obtained with fields which deflected the $\beta$ rays down towards the chamber. The numbers corresponding to the saturation currents obtained with

* Mackenzie, Phil. Mag. July 1907.

K 2 
different absorbing layers when the rays were deflected upwards and away from the chamber, are given in columns VI., VII., and VIII. of Table II, and curves $\mathrm{E}^{\prime}, \mathrm{F}^{\prime}$, and $\mathrm{G}^{\prime}$, which were drawn from these numbers, are shown in fig. 5 , and represent the conductivity when the rays were deffected in the opposite direction.

The short sharp rise in the curve $\mathrm{E}$ shows that with tinfoil $1.254 \mathrm{mms}$. in thickness the $\beta$ rays were still able to penetrate the absorbing layer. A slight rise, as can be seen from the figure, occurs in the curve $F$, but with the curve $G$ no evidence exists of any rise in conductivity. This curve, moreover, coincides with the curve $G^{\prime}$, which is drawn from values of the ionization obtained when the rays were deflected upwards; and this coincidence of the two curves $\mathrm{G}$ and $\mathrm{G}^{\prime}$ shows that with the absorbing layer with which the results illustrated by those curves were obtained, a thickness of tinfoil was finally reached which could not be penetrated by the $\beta$ rays, and by the secondary rays which were produced by them in the metal.

In order to find the precise thickness of tinfoil necessary to stop all the $\beta$ and $\beta$ secondary radiations, a curve shown in fig. 6 was plotted, taking as ordinates the ionization in the chamber dus to the maximum $\beta$ and $\beta$ secondary rays for each thickness of tinfoil, and as abscissa the thickness of the tinfoil screen with which each maximum was obtained. The maximum $\beta$ and $\beta$ secondary ionization for each thickness was determined in the following manner. Taking the results for a particular thickness, the limiting value of the ordinate of the curve drawn for a leflexion of the $\beta$ rays upward was subtracted from the maximum value of the ordinate of the curve drawn for deflexions of the $\beta$ rays downwards. Inasmuch as the limiting value of the ordinate of the former curve represented the ionization in the chamber dne to $\gamma$ rays and $\gamma$ secondary together with that due to natural causes, and the maximum value of the ordinate of the latter, the ionization due to the maximum $\beta$ and $\beta$ secondary, $\gamma$ and $\gamma$ secondary radiations with that due to natural causes, the difference gave the ionization due to maximum $\beta$ and $\beta$ secondary ionization for the particular thickness of tinfoil over the top of the ionization-chamber.

In Table III. there is collected and given in row $\mathrm{T}$. the maximum saturation currents in the chamber due to the $\beta$ and $\beta$ secondary, $\gamma$ and $\gamma$ secondary radiations, and that due to natural causes, for the screens of different thicknesses of tinfoil; in row II. the saturation-currents due to the $\gamma$ and $\gamma$ secondiry radiations and that due to natural causes, and 
in row III. the deduced maximum ionization due to the $\beta$ and $\beta$ secondary radiations for the same screens of tinfoil sheets.

TABLe III.

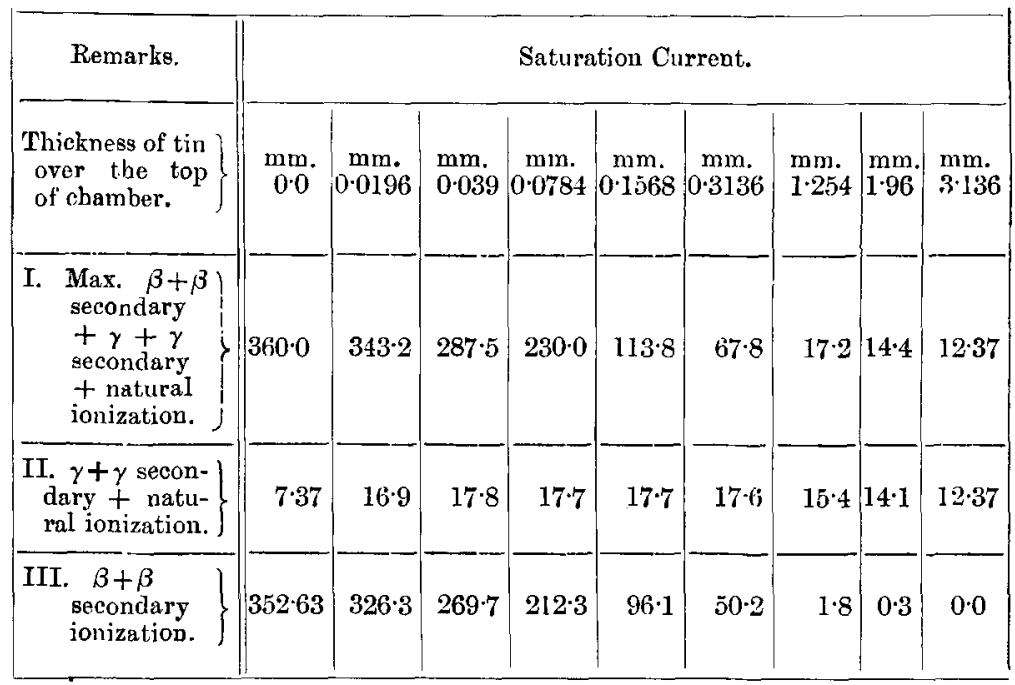

The ordinates of the curve in fig. 6 are the values of the maximum $\beta$ and $\beta$ secondary ionizations taken from row III. of the above table. The curve, as will be seen, is drawn with an initial rise, although no values were obtained from which the position of the highest point could be determined. Some observations to be given later, however, on the determination of the maximum thickness of aluminium necessary to absorb all the $\beta$ and $\beta$ secondary radiations, show clearly that for aluminium the ionization in the chamber due to the $\beta$ rays rose and fell as the thickness of aluminium was increased. The inference was therefore drawn that for all metals this rise and fall in the conductivity due to $\beta$ rays striking a wall of the chamber would occur, and would be made manifest if thin enough sheets of the metal were used.

From the regular manner in which the curve in fig. 6 falls away, it is clear that in the experiments with tinfoil the thickest sureen used was amply sufficient to absorb all the $\beta$ rays, and the secondary rays excited by them. An examination of the curve, moreover, makes it evident that even $a$ thickness of 2.5 millimetres of tinfoil was amply sufficient for that purpose. 


\section{B. Measurements on Reflected Rays.}

A series of measurements was also made on the secondary radiation produced at the front side of sheets of tinfoil when $\beta$ and $\gamma$ rays were allowed to fall on them. One layer of aluminium-foil $0065 \mathrm{~mm}$. in thickness was placed over the opening at the top of the chamber, and layers of tinfoil of increasing thickness were placed over the opening at the bottom. In these experiments, the capsule containing the radium bromide was placed vertically above the ionizationchamber, so that the rays, after passing between the poles of the magnet, impinged directly on the thin sheet of aluminiumfoil forming the upper wall of the ionization-chamber, and after passing through it, traversed the air in the chamber and then impinged on the tinfoil at the bottom. As the magnet was excited by increasing currents, the $\beta$ rays were more and more deflected until all were swept aside by the field and $\gamma$ rays alone entered the chamber.

\section{TABLE IV.}

Ionization by $\beta$ reflected Secondary Rays from Tinfoil.

\begin{tabular}{|c|c|c|c|c|c|c|c|c|}
\hline \multirow{2}{*}{$\begin{array}{l}\text { Current } \\
\text { in magnet. }\end{array}$} & \multicolumn{8}{|c|}{$\begin{array}{l}\text { Saturation Currents (arbitrary scale). } \\
\text { Different thicknesses of Tinfoil. }\end{array}$} \\
\hline & $\underset{0.0}{\mathrm{I} .}$ & 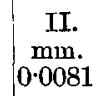 & $\begin{array}{c}\text { III. } \\
\text { mm. } \\
0 \cdot 0196\end{array}$ & $\begin{array}{l}\text { IV. } \\
\text { mm. } \\
0.039\end{array}$ & $\underset{\text { mim. }}{\mathrm{V} .}$ & $\begin{array}{c}\text { VI. } \\
\text { mm. } \\
0 \cdot 1568\end{array}$ & $\begin{array}{c}\text { VII. } \\
\text { min. } \\
0.6272\end{array}$ & $\begin{array}{l}\text { VIII. } \\
\text { mm. } \\
1.96\end{array}$ \\
\hline 0.0 & 1086 & 1121.9 & 1165 & 1198 & 1225 & 1230 & 1234 & 1230 \\
\hline 0.85 & & 826.4 & 858.2 & $864: 6$ & $\begin{array}{r}881.2 \\
\end{array}$ & $891 \cdot 4$ & $898 \cdot 4$ & 920 \\
\hline $0 \cdot 9$ & $821 \cdot 4$ & & & & & & & \\
\hline $2 \cdot 5$ & $267 \cdot 4$ & $230 \cdot 3$ & $224 \cdot 1$ & 2948 & $225 \cdot 7$ & $226 \cdot 3$ & $232 \cdot 1$ & $250 \cdot 2$ \\
\hline $4 \cdot 5$ & $103 \cdot 5$ & 104.5 & 95.8 & $98 \cdot 2$ & $91 \cdot 2$ & 95 & 95.0 & 86.4 \\
\hline $6 \cdot 75$ & 68.0 & $72 \cdot 3$ & 64.9 & 64.9 & 57.5 & 61.8 & 62.5 & 57.3 \\
\hline $10 \cdot 0$ & $58 \cdot 9$ & $61 \cdot 4$ & 53.9 & 554 & 47.6 & 51.5 & 50.8 & 47.7 \\
\hline $15 \cdot 0$ & $54 \cdot 2$ & $54 \cdot 7$ & $49 \cdot 1$ & $48 \cdot \overline{7}$ & 43.9 & $47 \cdot 3$ & $46 \cdot 7$ & $43 \cdot 5$ \\
\hline $22 \cdot 0$ & $51 \cdot 8$ & $50 \cdot 4$ & $46 \cdot 3$ & & $43 \cdot 4$ & 44.9 & 44.9 & $41 \cdot 0$ \\
\hline $23 \cdot 5$ & $\ldots$ & & & $46 \cdot 0$ & & & & \\
\hline $28 \cdot 5$ & $\ldots$ & $48 \cdot 5$ & $44 \cdot 7$ & $\ldots$ & $42 \cdot 6$ & $43 \cdot 2$ & $43 \cdot 0$ & \\
\hline $29 \cdot 5$ & $\ldots$ & $\ldots$ & $\ldots$ & $44 \cdot 7$ & & & & \\
\hline
\end{tabular}

In column II. Table IV. is given a typical set of these measurements, and a typical curve plotted from them is shown in fig. 7 . The values obtained with the complete set of reflectors ased are recorded in columns I. to VIII. of Table IV.: and it may be seen from the curve in fig. 7 that after a field corresponding to ten amperes was exceeded the ionization approached a limiting value which indicated that 
for magnetic fields excited by currents of ten amperes and greater, the $\beta$ rays were all turned aside, and the $\gamma$ rays alone were left to enter the chamber. The maximum ionization due to the $\beta$ and $\beta$ secondary, $\gamma$ and $\gamma$ secondary, and that due to natural causes is given by the ordinate of the initial point of this curve. With the interpretation given above the ionization due to the $\gamma, \gamma$ secondary, and to any radiations from the metal forming the walls of the chamber, may be taken to be represented by the point on the curve corresponding to the highest field. The difference between the values of these two ionizations gives a value for the maximum conductivity impressed upon the air by the $\beta$ rays, and by the secondary radiations excited by them in the tinfoil.

\section{Table V.}

\begin{tabular}{|c|c|c|c|}
\hline $\begin{array}{l}\text { Thickness of Tinfoil } \\
\text { over bottom of } \\
\text { chamber. }\end{array}$ & $\begin{array}{c}\text { Max. } \beta+\beta \\
\text { secondary } \\
+\gamma+\gamma \text { secon- } \\
\text { dary +natural } \\
\text { ionization. }\end{array}$ & $\begin{array}{c}\gamma+\gamma \text { secon- } \\
\text { dary + natural } \\
\text { ionization. }\end{array}$ & $\begin{array}{l}\text { Max. } \beta+\beta \\
\text { secondary } \\
\text { ionization. }\end{array}$ \\
\hline $\begin{array}{l}\quad \mathrm{mm} . \\
0.0000 \\
0.0081 \\
0.0196 \\
0.039 \\
0.0784 \\
0.1568 \\
0.6272 \\
1.96\end{array}$ & $\begin{array}{l}1086 \\
1121 \\
1165 \\
1198 \\
1225 \\
1230 \\
1234 \\
1230\end{array}$ & $\begin{array}{l}51 \cdot 8 \\
47 \cdot 5 \\
44 \cdot 7 \\
44 \cdot 7 \\
42 \cdot 6 \\
43 \cdot 2 \\
43 \cdot 2 \\
41 \cdot 5\end{array}$ & $\begin{array}{l}1034 \cdot 2 \\
1073 \cdot 5 \\
1116 \cdot 3 \\
1153 \cdot 3 \\
1182 \cdot 4 \\
1186 \cdot 8 \\
1190 \cdot 8 \\
1188 \cdot 5\end{array}$ \\
\hline
\end{tabular}

In Table $\nabla$. is given the deduced values of the maximum ionizations which were due to $\beta$ and $\beta$ secondary rays from similar sets of measurements for different thicknesses of tinfoil at the bottom of the chamber. The curve drawn in fig. 8 is plotted with ordinates representing the values of these maximum $\beta$ and $\beta$ secondary ionizations, as recorded in the fourth column of this table, and with abscissa representing the corresponding thicknesses of tinfoil. From this curve it is clear that the maximum conductivities produced by the $\beta$ and the reflected $\beta$ secondary rays reached a limiting value when the tinfoil sheets attained a thickness of $0.24 \mathrm{~mm}$., and for still greater thicknesses remained constant.

Summarizing all the results obtained with tinfoil it would then appear:- That when $\beta$.rays from radium are allowed to impinge on sheets of tinfoil, a maximum reflected secondary radiation is obtained when the tinfoil attains a thickness of $0.24 \mathrm{~mm}$.; and further, that a thiokness of $2.5 \mathrm{mms}$. of tinfoil 
is sufficient to absorb not only the transmitted secondary rays excited by $\beta$ rays, but also the whole of the primary radiation itself.

This result, however, while giving definite information regarding a lower limit to the thickness of tinfoil requisite to absorb primary $\beta$ rays, gives only an upper limit to the thickness necessary to absorb the transmitted secondary radiations produced by such rays. In order to obtain a lower limit to the thickness of tinfoil required to absorb the transmitted $\beta$ secondary radiation alone which is excited by $\beta$ rays, it would be necessary to modify considerably the arrangement of the apparatus used in making these measurements.

\section{Experiments on the Absorption and Deflexion of $\beta$ Rays by Lead.}

\section{A. Measurements on the Transmitted Rays through Lead.}

Experiments were conducted with lead in an exactly similar manner to those on the transmitted rays through tinfoil, in order to find the minimum thickness of lead necessary to prevent the emergence of any $\beta$ or $\beta$ secondary radiations from the far side of a plate upon which the primary $\beta$ rays of radium fell. The radium bromide was placed as in fig. 1 , and sets of readings were taken of the ionization in the chamber,-1st, with the top of the chamber open, and, 2nd, with it covered by lead-foil of varying thicknesses, the bottom of the chamber being always closed by a sheet of aluminiumfoil $.0065 \mathrm{~mm}$. in thickness. As before, these readings were taken as the $\beta$ rays were deflected downwards into the ionization-chamber, and upwards and away from it by different magneiic fields.

The sets of readings taken with the opening at the top of the chamber uncovered, and also covered with the lead-foil screens $0.241 \mathrm{~mm} ., 0.482 \mathrm{~mm} ., 0.723 \mathrm{~mm}$., and $0.964 \mathrm{~mm}$. in thickness respectively, are given in columns II., III., IV., and V. of Table VI. From the values of the ionizations given in columns III., IV., and V. of this table the curves A, B, and $\mathrm{C}$ (fig. 9) were drawn. The curves $\mathrm{A}^{\prime}, \mathrm{B}^{\prime}$, and $\mathrm{C}^{\prime}$, also shown in fig. 9 , were plotted from the numbers in columns III., IV., and V. of Table VII. Both sets of curves (it will be seen) are of the same type as those for the tinfoil which were fully discussed in Section If. A. 


\section{Table VI.}

Ionization by $\beta$ transmitted Secondary Rays from Lead-foil, with Primary Rays deflected down into Chamber.

\begin{tabular}{|c|c|c|c|c|c|}
\hline \multirow{2}{*}{$\begin{array}{l}\text { Current } \\
\text { in magnet } \\
\text { (amperes). }\end{array}$} & \multicolumn{5}{|c|}{$\begin{array}{l}\text { Saturation Current (arbitrary scale), with } \\
\text { different thicknesses of Lead-foil. }\end{array}$} \\
\hline & $\begin{array}{c}\mathrm{I} \\
\mathrm{mm} .\end{array}$ & $\begin{array}{l}\text { II. } \\
\text { mm. } \\
0 \cdot 241\end{array}$ & $\begin{array}{l}\text { III. } \\
\text { mm. } \\
0 \cdot 482\end{array}$ & $\begin{array}{l}\text { IV. } \\
\text { mm. } \\
0723\end{array}$ & $\begin{array}{l}V . \\
\text { mm. } \\
0.964\end{array}$ \\
\hline $\begin{array}{l}0.0 \\
0 \cdot 2\end{array}$ & $\begin{array}{l}56.5 \\
95.8\end{array}$ & $21 \cdot 1$ & $19 \cdot 6$ & $16 \cdot 9$ & 16.5 \\
\hline $\begin{array}{l}0 \cdot 85 \\
1 \cdot 35\end{array}$ & $\begin{array}{l}294 \cdot 8 \\
383 \cdot 3\end{array}$ & $21 \cdot 9$ & $\ldots$ & $\ldots$ & $16 \cdot 3$ \\
\hline 1.70 & $359 \cdot 3$ & & & & \\
\hline $2 \cdot 5$ & $302 \cdot 6$ & $30 \cdot 0$ & $20 \cdot 4$ & $16 \cdot 9$ & $16 \cdot 2$ \\
\hline $\begin{array}{l}4: 0 \\
4: 5\end{array}$ & $\dddot{118} \cdot 5$ & 487 & 2266 & $\ddot{170}$ & $15 \times 9$ \\
\hline $5 \cdot 0$ & $\ldots$ & $50 \cdot 4$ & $24 \cdot 8$ & 17.4 & \\
\hline $\begin{array}{l}6 \cdot 5 \\
7 \cdot 0\end{array}$ & $68 \cdot 0$ & $\cdots$ & $25 \cdot 4$ & $17 \cdot 34$ & $15 \cdot 8$ \\
\hline $10 \cdot 0$ & $41 \cdot 5$ & $35 \cdot 4$ & $24 \cdot 0$ & $17 \cdot 03$ & $15 \cdot 7$ \\
\hline $15 \cdot 0$ & 26.4 & $27 \cdot 9$ & $21 \cdot 6$ & $16 \cdot 45$ & $15 \cdot 4$ \\
\hline $22 \cdot 5$ & $18 \cdot 0$ & $23 \cdot 3$ & $19 \cdot 5$ & $16 \cdot 25$ & $15 \cdot 4$ \\
\hline
\end{tabular}

\section{Table VII.}

Ionization by $\beta$ transmitted Secondary Rays from Lead-foil, with Primary Rays deflected up from Chamber.

\begin{tabular}{|c|c|c|c|c|c|}
\hline \multirow{2}{*}{$\begin{array}{l}\text { Current } \\
\text { in magnet } \\
\text { (amperes). }\end{array}$} & \multicolumn{5}{|c|}{$\begin{array}{l}\text { Saturation Current (arbitrary scale) for } \\
\text { different thicknesses of Lead-foil. }\end{array}$} \\
\hline & $\underset{0.0}{\mathrm{I} .}$ & $\begin{array}{l}\text { II. } \\
\mathrm{mm} . \\
0 \cdot 241\end{array}$ & $\begin{array}{l}\text { III. } \\
\text { mm. } \\
0 \cdot 482\end{array}$ & $\begin{array}{l}\text { IV. } \\
\text { mm. } \\
0.723\end{array}$ & $\begin{array}{c}\nabla . \\
0.964\end{array}$ \\
\hline 0 & 56.5 & $21 \cdot 1$ & $19 \cdot 5$ & $16 \cdot 9$ & $16 \cdot 5$ \\
\hline 0.8 & $18 \cdot 5$ & $2 v \cdot 1$ & & & 163 \\
\hline $2 \cdot 5$ & $9 \cdot 4$ & 200 & 190 & $16 \cdot 7$ & $16 \cdot 1$ \\
\hline $4 \cdot 5$ & $\ldots$ & 197 & $18 \cdot 8$ & $16 \cdot 59$ & 16.0 \\
\hline 6.5 & $8 \cdot 6$ & $19 \cdot 5$ & & & \\
\hline 7.0 & & & $18 \cdot 5$ & 1671 & 158 \\
\hline $10^{\circ} 0$ & $\cdots$ & $19 \cdot 1$ & 185 & & $15 \cdot 7$ \\
\hline 150 & $8 \cdot 1$ & $19 \cdot 0$ & $18 \cdot 1$ & $16 \cdot 15$ & 15.5 \\
\hline $22 \cdot 5$ & $8 \cdot 1$ & $19 \cdot 1$ & $18 \cdot 0$ & $16 \cdot 28$ & $15 \cdot 4$ \\
\hline
\end{tabular}


The curve B, drawn for a thickness of $723 \mathrm{~mm}$. of lead, indicates that $\beta$ rays which were deflected by a field corresponding to about 6 amperes, penetrated this thickness of lead, while the coincidence of the curves $C^{\prime}$ and $C^{\prime}$ drawn from the values corresponding both to the upward and downward deflexions of the $\beta$ rays when $964 \mathrm{~mm}$. was the thickness of the lead screen, shows clearly that the $\beta$ and also the $\beta$ secondary rays could not pass through this thickness of lead.

As is fully explained in Section III. A, the maximum value of the conductivities in the chamber due to $\beta$ and $\beta$ secondary rays for the different thicknesses of the screens can readily be deduced from the tables given above. These deduced values are given in row III. of Table VIII., and a curve representing them is shown in fig. 10. From the

Table VIII.

\begin{tabular}{|c|c|c|c|c|c|}
\hline Remarks. & \multicolumn{5}{|c|}{ Saturation Currert. } \\
\hline $\left.\begin{array}{c}\text { Thickness of lead over } \\
\text { the top of chamber. }\end{array}\right\}$ & $\underset{0}{\operatorname{mim}}$ & $\mathrm{mm}_{\cdot 24}$ & ${ }^{\mathrm{mm}} \cdot 482$ & $\mathrm{~mm}_{\cdot 723}$ & mm. \\
\hline 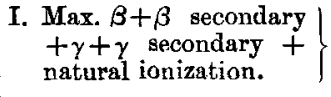 & $383 \cdot 2$ & $50 \cdot 9$ & $25 \cdot 8$ & $17 \cdot 5$ & $15 \cdot 6$ \\
\hline II. $\gamma+\gamma$ secondary +$\}$ & $8 \cdot 4$ & $19 \cdot 4$ & $17 \cdot 7$ & $16 \cdot 5$ & $15 \cdot 6$ \\
\hline $\left.\begin{array}{l}\text { III. Max. } \beta+\beta \text { secon- } \\
\text { dary ionization. }\end{array}\right\}$ & $374 \cdot 8$ & $31 \cdot 5$ & $8 \cdot 1$ & $1 \cdot 0$ & 0 \\
\hline
\end{tabular}

curve it is evident that a screen of lead $\cdot 9 \mathrm{~mm}$. in thickness completely absorbed all of the $\beta$ and the $\beta$ secondary radiations excited in the lead, including the most penetrating.

\section{B. Measurements on Reflected Rays from Lead.}

In this set of measurements the arrangement of the apparatus was the same as when the measurements on the reflected rays from tin were taken, the radium being placed vertically above the ionization-chamber. Different thicknesses of lead were placed over the opening at the bottom, while the single sheet of aluminium-foil, $0065 \mathrm{~mm}$. in thickness, covered the top. As before, the saturationcurrents in the chamber were taken as the magnetic field deflected the $\beta$ rays farther and farther from the opening of 
the chamber; and the values of the saturation-currents are given in columns I., II., III., IV., V., and VI. of Table IX.

Table IX.

Ionization by $\beta$ reflected Secondary Rays from Lead-foil.

\begin{tabular}{|c|c|c|c|c|c|c|}
\hline \multirow{2}{*}{$\begin{array}{l}\text { Current } \\
\text { in magnet } \\
\text { (amperes). }\end{array}$} & \multicolumn{6}{|c|}{$\begin{array}{l}\text { Saturation Current (arbitrary scale), with } \\
\text { different thicknesses of Lead-foil. }\end{array}$} \\
\hline & $\begin{array}{c}\mathrm{I} . \\
\mathrm{mm} . \\
0.0\end{array}$ & $\begin{array}{c}\text { II. } \\
\mathrm{mm} . \\
0 \cdot 066\end{array}$ & $\begin{array}{l}\text { III. } \\
\text { mm. } \\
0.093\end{array}$ & $\begin{array}{l}\text { IV. } \\
\text { mm. } \\
0 \cdot 116\end{array}$ & $\begin{array}{c}\nabla . \\
\mathrm{mm} . \\
0.241\end{array}$ & $\begin{array}{l}\text { VI. } \\
\text { mnl. } \\
0.964\end{array}$ \\
\hline 0.0 & $1161 \cdot 0$ & $1315 \cdot 0$ & $1337 \cdot 0$ & $1349 \cdot 0$ & $1349^{\circ} 0$ & $1340 \cdot 0$ \\
\hline 08 & $799-0$ & - & $809 \cdot 8$ & $\ldots$ & $818 \cdot 5$ & $801 \cdot 3$ \\
\hline $2 \cdot 5$ & 1460 & $\ldots$ & 147.8 & ... & $139 \cdot 8$ & $145 \cdot 0$ \\
\hline $4 \cdot 5$ & 64.9 & $\ldots$ & 59.5 & $\ldots$ & $65 \cdot 3$ & 638 \\
\hline 6.5 & $58 \cdot 9$ & $\cdots$ & 547 & $\ldots$ & $54 \cdot 2$ & $55 \cdot 5$ \\
\hline 100 & $57 \cdot 8$ & $\cdots$ & $56 \cdot 3$ & $58 \cdot 3$ & $56 \cdot 1$ & \\
\hline 150 & $58 \cdot 9$ & $57 \cdot 8$ & 586 & $58 \cdot 0$ & & $56 \cdot 6$ \\
\hline $22 \cdot 0$ & $57 \cdot 8$ & $56 \cdot 9$ & $57 \cdot 2$ & $56 \cdot 6$ & $56 \cdot 9$ & 56.9 \\
\hline $28 \cdot 0$ & $56 \cdot 9$ & $56 \cdot 1$ & $56 \cdot 3$ & $56 \cdot 0$ & $55 \cdot 3$ & $55 \cdot 8$ \\
\hline
\end{tabular}

From these it will be seen that with the lead reflectors of different thicknesses, the saturation currents were practically the same when magnetic fields of sufficient strength to deflect all the $\beta$ rays were applied. In order to ascertain the maximum ionization for the various lead reflectors due to the $\beta$ ray effect, the mean of the readings obtained with the high fields was taken as representing the conductivity due to $\gamma$ radiations, that due to the secondary radiations excited by these in the reflectors, and also that due to the so-called natural ionization. This mean was subtracted from the maximum ionization obtained with each of the reflectors before the application of a magnetic field, and the differences, which are recorded in column IV. of Table X.

Table X.

\begin{tabular}{|c|c|c|c|}
\hline $\begin{array}{c}\text { Thickness } \\
\text { of lead } \\
\text { over buttom } \\
\text { of chamber. }\end{array}$ & $\begin{array}{c}\text { Max. } \beta+\beta \text { secondary } \\
+\gamma+\gamma \text { secondary+ } \\
\text { natural ionization. }\end{array}$ & $\begin{array}{c}\gamma+\gamma \text { secondary }+ \\
\text { natural ionization. }\end{array}$ & $\begin{array}{c}\text { Max. } \beta+\beta \\
\text { secondary } \\
\text { ionization. }\end{array}$ \\
\hline mm. & 1161 & $57 \cdot 8$ & \\
$0 \cdot 0$ & 1315 & $56 \cdot 9$ & $1103 \cdot 2$ \\
0.066 & 1337 & $56 \cdot 7$ & $1258 \cdot 1$ \\
$0 \cdot 093$ & 1349 & $57 \cdot 3$ & $1280 \cdot 3$ \\
$0 \cdot 116$ & 1349 & $55 \cdot 6$ & $1291 \cdot 7$ \\
$0 \cdot 241$ & 1340 & $56 \cdot 2$ & 1293.4 \\
0.964 & & & \\
\hline
\end{tabular}


and represented araphically by the enrve $A$ in fig. 11 , were taken to represent the ionizations produced in the chamber by the primary $\beta$ rays and by the secondary rays excited by them in the lead reffectors. From a consideration of these values and of the form of the curve in fig. 11, it is evident that a maximum secondary radiation, due to the impact of $\beta$ rars on the lead reflectors, was obtained with a thickness of $\cdot 16 \mathrm{~mm}$. of this metal.

From these results, then, it is clear that the secondary radiation emitted by the front side of a lead plate upon which the $\beta$ rays from radium fall, do not come from a depth of the metal greater than $16 \mathrm{~mm}$. It is also established by the results that a plate of lead $9 \mathrm{~mm}$. in thickness will completely absorb all the primary $\beta$ rays from radium, as well as all the secondary radiation excited by these rays in the lead plate.

\section{Experiments on the Absorption and Reflexion of $\beta$ Rays by Azuminium-Foil.}

\section{A. Measurements on Transmitted Rays.}

A series of readings was also made with a number of different thicknesses of absorbing layers of aluminium-foil over the top of the chamber, in order to find the minimum thickness of aluminium necessary to stop the $\beta$ rays. The bottom of the chamber was closed by the same sheet of aluminium-foil, $\cdot 0065 \mathrm{~mm}$. thick, used throughout these experiments. As before, the first series of measurements was taken without any cover over the top of the chamber; and this series is given in column $\mathrm{I}$. of Table XI. The results obtained with laycrs $\cdot 0065 \mathrm{~mm} ., \cdot 28 \mathrm{~mm}$., $1 \cdot 184 \mathrm{~mm}$, $3.41 \mathrm{~mm}$., $4.73 \mathrm{~mm}$, and $8.14 \mathrm{~mm}$. in thickness respectively, are given in columns II., III., IV., V., VI., VII. of the same Table.

The curves A, B, C, D, and $\mathrm{E}$, shown in figs. 12 and 13 , are plotted from the results given in columns I., II., IV., VI., and VII. of Table XI. ; and curves $\mathrm{D}^{\prime}$ and $\mathrm{E}^{\prime}$, fig. 13, from the results given in columns VI. and VII. of Table XII.

On comparing the results obtained when there was no metallie evering over the opening at the top of the ionizationchamber with the results when a covering of $0.0065 \mathrm{~mm}$. of aluminium was used, it is readily seen that the addition of the covering considerably increased the maximum ionization in the chamber as the $\beta$ rays were deflected into it. This effect is also brought out very clearly by the curves $A$ and $B$ 


\section{TABLE XI.}

Ionization by $\beta$ transmitted Secondary Rays from Aluminiumfoil with Primary Rays deflected down into Chamber.

\begin{tabular}{|c|c|c|c|c|c|c|c|}
\hline \multirow{2}{*}{$\begin{array}{c}\text { Current } \\
\text { in magnet } \\
\text { (amperes). }\end{array}$} & \multicolumn{7}{|c|}{$\begin{array}{l}\text { Saturation Current (arbitrary scale), with different thicknesses } \\
\text { of Aluminium-foil. }\end{array}$} \\
\hline & $\underset{0.0}{\mathrm{I} .}$ & $\begin{array}{c}\text { II. } \\
\text { mm. } \\
0.0065\end{array}$ & $\begin{array}{l}\text { III. } \\
\mathrm{mm} . \\
028\end{array}$ & $\begin{array}{c}\mathrm{IV} . \\
\mathrm{mm} . \\
1 \cdot 184\end{array}$ & $\begin{array}{l}\mathrm{v} . \\
\mathrm{mm} .\end{array}$ & $\begin{array}{l}\text { VI. } \\
\text { mm. } \\
4 \cdot 73\end{array}$ & $\begin{array}{l}\text { VII. } \\
\text { mm. } \\
8 \cdot 14\end{array}$ \\
\hline 0.0 & $77 \cdot 6$ & 657 & $25 \cdot 7$ & $14 \cdot 6$ & 13.99 & $13 \cdot 12$ & $12 \cdot 32$ \\
\hline 0.2 & $117 \cdot 3$ & $100 \cdot 8$ & & & & & \\
\hline 0.45 & 176.9 & 157.5 & $36 \cdot 2$ & & & & \\
\hline 0.8 & $302 \cdot 6$ & 3194 & $63 \cdot 1$ & $15 \cdot 7$ & 13.97 & 13.24 & \\
\hline $1 \cdot 3$ & 3650 & 396.5 & & & & & \\
\hline $1 \cdot 65$ & $359 \cdot 3$ & $396 \cdot 5$ & $280 \cdot 4$ & $22 \cdot 2$ & 14.57 & & \\
\hline $2 \cdot 5$ & 294.8 & $319 \cdot 4$ & $287 \cdot 5$ & $50 \cdot 4$ & $15 \cdot 65$ & 1315 & \\
\hline $4 \cdot 5$ & 111.6 & 127.7 & $111 \cdot 6$ & $73 \cdot 2$ & $17 \cdot 42$ & $13 \cdot 22$ & $12 \cdot 24$ \\
\hline 6.5 & $63 \cdot 1$ & 74.2 & 680 & 53.7 & $20 \cdot 31$ & 13.42 & $12 \cdot 22$ \\
\hline $10 \cdot 0$ & $37 \cdot 4$ & $43 \cdot 2$ & $22 \cdot 7$ & $35 \cdot 5$ & & 13.42 & $12 \cdot 15$ \\
\hline $15 \cdot 0$ & $25 \cdot 1$ & $18 \cdot 4$ & $27 \cdot 9$ & 23.8 & $16 \cdot 64$ & 13.17 & $12 \cdot 13$ \\
\hline 22.0 & $18 \cdot 6$ & $20 \cdot 9$ & $20 \cdot 1$ & $18 \cdot 1$ & $15 \cdot 37$ & 13.08 & 12.09 \\
\hline
\end{tabular}

\section{TABLE XII.}

Ionization by $\beta$ transmitted Secondary Rays from Aluminium. foil with Primary Rays deflected up from Chamber.

\begin{tabular}{|c|c|c|c|c|c|c|c|}
\hline & \multicolumn{7}{|c|}{ Saturation Current (arbitrary scale) for different thicknesses } \\
of Aluminium-foil.
\end{tabular}

in fig. 12. This increase in ionization in the chamber due to the thin covering of aluminium was interpreted as being due to the action of secondary radiation. The small thickness of aluminium-foil used would only absorb a very small proportion of the primary $\beta$ rays, and consequently it would be possible for the excited secondary rays to make a contribution 
to the ionization in the chamber greater than the loss incurred by the absorption of the primary rays. Of course it is also possible that the increase in ionization observed could be interpreted as being due to a decrease in velocity impressed upon the primary rays by their passage through the foil. It is to be noted, too, in connexion with this explanation that, since the values of the ionization shown by curve $A$ were obtained with the opening at the top of the chamber uncovered, these undoubtedly represented the ionization of a somewhat larger body of air than was used in the experiments when the opening was covered. It follows, therefore, that the real increase in ionization produced by the passage of the $\beta$ rays through the single sheet of aluminium should have been greater than that indicated by the curves A and B of fig. 12. Some measurements were made with screens of two and of three sheets of aluminium; and as these were found to give maximum ionizations approximately the same as that obtained with a single sheet, it was seen that, in order to investigate more fully this rise in conductivity, it would be necessary to use still thinner sheets of aluminium than the one with which the opening was first closed. As this point was not specially pertinent to the subject under investigation by the writer, its examination was deferred. This rise in conductivity resulting from the passage of $\beta$ rays through a thin layer of aluminium was not observed in the experiments with lead and tin screens, doubtless because the least thicknesses of these metals absorbed more of the primary $\beta$ rays than could be compensated for by the excited secondary radiations. This result, it will be remembered, was referred to in Section III. A, and was given as a reason for drawing the curve shown in fig. 6 with an additional rise, although no determinations were made with which it could be confirmed.

Curve C shows that while the more deflectable of the $\beta$ radiations were absorbed by $1 \cdot 184 \mathrm{~mm}$. of aluminium-foil, the more penetrating still passed through it. The slight rise in carve $D$ also indicates that some of the $\beta$ radiation was still able to penetrate $4.73 \mathrm{~mm}$. of aluminium. With a thickness of $8.14 \mathrm{~mm}$. of aluminium, however, no rise in the conductivity occurred, and, as curve $\mathrm{E}$ (fig. 13) shows, this thickness was sufficient to cut off all the $\beta$-ray effect.

It will be seen that the eurves which are drawn on a large scale for deflexions of $\beta$ rays downwards, and for deflexions of these rays upwards, corresponding to a thickness of $8.14 \mathrm{mms}$. of aluminium over the opening at the top of the chamber and denoted by $\mathrm{E}$ and $\mathrm{E}^{\prime}$, do not coincide. It will be recalled, further, that the curves drawn for the limiting thicknesses 
of tin and lead under the same conditions showed an exact coincidence. This peculiarity in the behaviour of the aluminium screen was investigated at considerable length, and was finally shown by some experiments which are described later in Section VI. to be due to the action of the secondary rays excited on the far side of the thicker aluminium screens by the $\gamma$ rays entering the chamber.

\section{TABLE XIII.}

\begin{tabular}{|c|c|c|c|c|c|c|c|}
\hline Remarks. & \multicolumn{7}{|c|}{ Saturation Ourrent. } \\
\hline $\begin{array}{c}\text { Thickness of aluminium } \\
\text { over the top of obamber }\}\end{array}$ & $\underset{0.0}{\mathrm{~mm}}$ & $\begin{array}{c}\mathrm{mm} . \\
0.0065\end{array}$ & $\operatorname{mm}_{0 \cdot 28}$ & $\mathrm{~mm}$. & $\begin{array}{l}\text { mm. } \\
3 \cdot 41\end{array}$ & ${ }_{4.73}^{\mathrm{nm}}$ & $\operatorname{mm}_{8 \cdot 14}$ \\
\hline $\left.\begin{array}{c}\text { I. Max. } \beta+\beta \text { secondary } \\
+\gamma+\gamma \text { secondary }+ \\
\text { nutural ionization...... }\end{array}\right\}$ & 365 & $396 \cdot 5$ & $287 \cdot 5$ & $79 \cdot 3$ & $20 \cdot 3$ & $13 \cdot 5$ & $12 \cdot 2$ \\
\hline $\left.\begin{array}{r}\text { II. } \gamma+\gamma \text { secondary }+\} \\
\text { natural ionization....... }\end{array}\right\}$ & $12 * 6$ & $10 \cdot 2$ & 11 & $12 \cdot 3$ & $13 \cdot 1$ & $12 \cdot 3$ & $11 \cdot 7$ \\
\hline $\begin{array}{l}\text { III. Max. } \beta+\beta \text { secondary } \\
\text { ionization } \ldots \ldots \ldots \ldots \ldots . .\end{array}$ & $352 \cdot 4$ & $386 \cdot 3$ & $276 \cdot 5$ & $67 \cdot 0$ & $7 \cdot 2$ & $1 \cdot 2$ & 0.5 \\
\hline ................ & $332 \cdot 4$ & $386 \cdot 3$ & $2 \pi 65$ & $67 \cdot 0$ & $6 \cdot 7$ & 07 & 0.0 \\
\hline
\end{tabular}

In Table XIII. there is given in row I. the maximum saturation-currents in the chamber due to the $\beta$ and $\beta$ secondary, $\gamma$ and $\gamma$ secondary radiations, and that due to natural causes for the different thicknesses of aluminium-foil ; in row II. saturation-currents due to the $\gamma$ and $\gamma$ secondary radiation and that due to natural causes; and in row III. the maximuum ionizations due to the $\beta$ and $\beta$ secondary radiations deduced, as explained in Section III. A, from the Tables above and their corresponding curves. On looking at the figures given in row III. of this table, it is seen that there is apparently a $\beta$-ray ionization of 5 , or about one-seventh of one per cent. of the greatest $\beta$-ray ionization in the chamber when the top of the chamber is covered by $8.14 \mathrm{~mm}$. of aluminium. This conductivity, however, represents really a $\gamma$-ray effect, due, as said before, to the thickness of the aluminium used, and should be deducted from the last three of the numbers given in row III. of the table. These corrected values of the maximum $\beta$ and $\beta$ secondary ionizations are given in row IV., and a curve (fig. 14) is plotted from these values. An examination of this curve makes it evident that a thickness 
of approximately $7 \mathrm{~mm}$. of aluminium-foil was amply sufficient to absorb all the $\beta$ rays and the secondary rays excited by them.

B. Measurements on Reflected Rays from Aluminium.

A series of measurements was also made on the secondary radiation produced at the front side of sheets of aluminium-foil when $\beta$ and $\gamma$ rays were allowed to fall on them; and from these the critical depth of the $\beta$-ray effect has been determined. The arrangement of the apparatus was the same as for the measurements on the reflected radiations from tin and lead. The values of the saturation-currents in the chamber found for the different thicknesses of aluminium-foil at the bottom are given in Table XIV., and the maximum ionizations due to the $\beta$ rays have been deduced from these tables and their corresponding curves. These maximum currents are given in Table XV., and the curve in fig. 15 plotted from

TABLE XIV.

Ionization by $\beta$ reflected Secondary Rays from Aluminium.

\begin{tabular}{|c|c|c|c|c|c|}
\hline \multirow{2}{*}{$\begin{array}{l}\text { Current } \\
\text { in magnet } \\
\text { (amperes). }\end{array}$} & \multicolumn{5}{|c|}{$\begin{array}{l}\text { Saturation Current (arbitrary scale), with } \\
\text { different thicknesses of Aluminium-foil. }\end{array}$} \\
\hline & $\underset{\substack{\mathrm{I} \\
\mathbf{m m} . \\
0.0065}}{.}$ & $\begin{array}{c}\text { II. } \\
\text { mm. } \\
0 \cdot 026\end{array}$ & $\begin{array}{c}\text { III. } \\
\text { mm. } \\
0.065\end{array}$ & $\begin{array}{c}\text { IV. } \\
\text { mm. } \\
0.280\end{array}$ & $\begin{array}{l}\text { V. } \\
\text { min. } \\
0.963\end{array}$ \\
\hline $\begin{array}{l}0.0 \\
0.8\end{array}$ & $\begin{array}{r}1106.0 \\
709.8\end{array}$ & $\begin{array}{r}11260 \\
7165\end{array}$ & $1140^{\circ} 0$ & 1176.0 & $1181 \cdot 0$ \\
\hline 0.85 & & & $684: 3$ & $710 \cdot 0$ & 723.9 \\
\hline $2 \cdot 5$ & $127 \cdot 1$ & $128 \cdot 9$ & 116.5 & 1258 & $170 \cdot 4$ \\
\hline $4 \cdot 5$ & $66 \cdot 8$ & $58 \cdot 6$ & $65 \cdot 7$ & $59 \cdot 2$ & $62 \cdot 1$ \\
\hline 6.5 & $57 \cdot 4$ & $52 \cdot 0$ & 55 & $49 \cdot 5$ & $52 \cdot 9$ \\
\hline $15 \cdot 0$ & $57 \cdot 7$ & $55 \cdot 2$ & 58.0 & 543 & 532 \\
\hline $23 \cdot 0$ & $56 \cdot 1$ & $54 \cdot 5$ & $56 \cdot 6$ & $53 \cdot 4$ & 525 \\
\hline $30 \cdot 0$ & $\ldots$ & 53.4 & 547 & 520 & 51.5 \\
\hline
\end{tabular}

TABLE XV.

\begin{tabular}{|c|c|c|c|}
\hline $\begin{array}{c}\text { Thickness of } \\
\text { aluminium-foil } \\
\text { over bottom } \\
\text { of chamber. }\end{array}$ & $\begin{array}{c}\text { Max. } \beta+\beta \\
\text { secondary }+\gamma+\gamma \\
\text { secondary+ } \\
\text { natural ionization. }\end{array}$ & $\begin{array}{c}\gamma+\gamma \text { secondary } \\
\text { +uatural } \\
\text { ionization. }\end{array}$ & $\begin{array}{c}\text { Max. } \beta+\beta \\
\text { secondary } \\
\text { ionization. }\end{array}$ \\
\hline mm. & 1106 & $57 \cdot 1$ & $1048 \cdot 9$ \\
$0 \cdot 0065$ & 1126 & $53 \cdot 8$ & $1072 \cdot 2$ \\
0.026 & 1140 & $56 \cdot 2$ & 10838 \\
0.065 & 1176 & $52 \cdot 3$ & $1123 \cdot 7$ \\
0.280 & 1181 & $52 \cdot 5$ & $1128 \cdot 5$ \\
0.963 & & & \\
\hline
\end{tabular}


ther shows the manner in which the intensity of the secondary radiation excited by the $\beta$ rays rose as the thickness of the aluminium was increased. From this curve it is evident that the maximum conductivity produced by the $\beta$ and the refected $\beta$ secondary rays attaincd a limiting value when the aluminium-foil sheets reached a thickness of ' $4 \mathrm{~mm}$.

It follows, then, from these results that a thickness of $7 \mathrm{~mm}$. of aluminium will completely absorb all the $\beta$ rays from radium and the secondary rays which they excite in the metal. It follows, too, that the secondary rays emitted by the front side of a plate of the metal when bonibarded by the $\beta$ rays from radium do not come from a depth in the metal greater than $.4 \mathrm{~mm}$.

\section{Experiments on the Secondary R.ays excited in Aluminium by $\gamma$ Rays.}

It has been stated in Section V. A, that when a sheet of aluminium $8.1 \mathrm{~mm}$. in thickness, which was sufficient to absorball the $\beta$ rays and the secondary rays excited by them, was placed over the opening at the top of the ionizationchamber, the saturation-currents were not the same with a magnetic field applied in one direction as those obtained with the sume field reversed. This lack of symmetry in the values of the saturation-currents obtained when screens of aluminium were used, is illustrated by curves $E$ and $E^{\prime}$ in fig. 13. In the experiments with lead and tin screens no effect of this kind was observed; and in order to clear up the matter, an additional series of experiments was carried out to ascertain, if possible, the cause of it in the case of aluminium.

(1) In the first experiment a thickness of $4.73 \mathrm{mms}$. of aluminium was placed over the opening at the top of the chamber, and above this a thickness of $.964 \mathrm{~min}$. of lead. This thickness of lead, it will be remembered, was found in the earlier experiments sufficient to absorb all the $\beta$ and the $\beta$ secondary radiations. It follows, then, that with this screen none but the $\gamma$ rays of radium could enter the ionizationchamber when this double thickness of lead and aluminium was placed over the top. The conductivities in the chamber for gradually increasing fields in both directions were taken, and these are given in Table XVI. The second column of

Phil. Mag. S. 6. Vol. 17. No. 97. Jan. 1909, $I_{1}$ 


\section{TABLE XVI.}

Thickness of lead over the top of chamber $=.964 \mathrm{~mm}$. Thickness of aluminium over the top of chamber $=4.73 \mathrm{mms}$.

Lead above aluminium.

\begin{tabular}{|c|c|c|c|}
\hline \multicolumn{2}{|c|}{$\begin{array}{c}\beta \text { rays deflected towards } \\
\text { chamber. }\end{array}$} & \multicolumn{2}{|c|}{$\begin{array}{c}\beta \text { rays deflected away from } \\
\text { chamber. }\end{array}$} \\
\hline $\begin{array}{c}\text { Current } \\
\text { through } \\
\text { magnet } \\
\text { (amperes). }\end{array}$ & $\begin{array}{l}\text { Saturation } \\
\text { Current. }\end{array}$ & $\begin{array}{c}\text { Current } \\
\text { through } \\
\text { magnet } \\
\text { (amperes). }\end{array}$ & $\begin{array}{l}\text { Saturation } \\
\text { Current. }\end{array}$ \\
\hline $\begin{array}{r}0 \cdot 0 \\
2 \cdot 5 \\
4 \cdot 5 \\
6 \cdot 5 \\
10 \cdot 0 \\
15 \cdot 0 \\
22 \cdot 0\end{array}$ & $\begin{array}{l}10 \cdot 85 \\
10 \cdot 94 \\
10 \cdot 87 \\
10 \cdot 89 \\
10.70 \\
10.67 \\
10.65\end{array}$ & $\begin{array}{r}0 \cdot 0 \\
2 \cdot 5 \\
4 \cdot 5 \\
6 \cdot 5 \\
10 \cdot 0 \\
15 \cdot 0 \\
21 \cdot 0\end{array}$ & $\begin{array}{r}10 \cdot 68 \\
10 \cdot 74 \\
10 \cdot 37 \\
10 \cdot 10 \\
9 \cdot 88 \\
9 \cdot 7 \pm \\
9 \cdot 60\end{array}$ \\
\hline
\end{tabular}

this table shows a slight gradual decrease in ionization as the $\beta$ rays were deflected downwards toward the chamber, and the fourth column shows a greater decrease as the $\beta$ rays were deflected away from it. Here, again, it will be seen that the difference in the ionizations for the directions of the magnetic field was approximately of the same magnitude as when there was $8.4 \mathrm{~mm}$. of aluminium over the ionization-chamber. Since none but $\gamma$ rays could enter the chamber, this difference in ionization must have been due to the action of the magnetic field in the chamber on the secondary radiation issuing from the back of the aluminium screen under the excitation of the $\gamma$ rays.

(2) The next experiment was to place the radium protected by the lead cylinder on the side of the ionization-chamber directly opposite to its former position. The same aluminium screen, $8.14 \mathrm{~mm}$. in thickness, was placed over the chamber as before, and the $\beta$ rays were again deflected down into the chamber by a suitably directed magnetic field and afterwards upward and away from it with the field reversed. The results are given in Table XVII. The numbers thus recorded show the same characteristics as when the radium was in the first position. When the magnetic fields were such as to deflect the $\beta$ rays downwards into the chamber, the ionization decreased but slightly. On the other hand, a considerably greater decrease took place when the $\beta$ rays were deflected in the opposite direction. 


\section{TABLE XVII.}

Thickness of aluminium over the top of chamber $=8.14 \mathrm{mms}$. Radium on opposite side of chamber from its usual position.

\begin{tabular}{|c|c|c|c|}
\hline \multicolumn{2}{|c|}{$\begin{array}{c}\beta \text { rays deflected towards } \\
\text { chamber. }\end{array}$} & \multicolumn{2}{|c|}{$\begin{array}{c}\beta \text { rays deflocted away from } \\
\text { chamber. }\end{array}$} \\
\hline $\begin{array}{c}\text { Current } \\
\text { through } \\
\text { magnet } \\
\text { (amperes). }\end{array}$ & $\begin{array}{l}\text { Saturation } \\
\text { Current. }\end{array}$ & $\begin{array}{c}\text { Current } \\
\text { through } \\
\text { magnet } \\
\text { (amperes). }\end{array}$ & $\begin{array}{l}\text { Saturation } \\
\text { Current. }\end{array}$ \\
\hline $\begin{array}{r}0 \cdot 0 \\
4 \cdot 5 \\
10 \cdot 0 \\
15 \cdot 0 \\
22 \cdot 5\end{array}$ & $\begin{array}{l}12 \cdot 50 \\
12 \cdot 46 \\
12 \cdot 43 \\
12 \cdot 41 \\
12 \cdot 40\end{array}$ & $\begin{array}{c}0 \cdot 0 \\
0.85 \\
2 \cdot 5 \\
4 \cdot 5 \\
7 \cdot 0 \\
10 \cdot 0 \\
150 \\
22 \cdot 5\end{array}$ & $\begin{array}{l}12.56 \\
12.43 \\
12 \cdot 32 \\
12.06 \\
11.76 \\
11.43 \\
11 \cdot 11 \\
10.91\end{array}$ \\
\hline
\end{tabular}

(3) A third experiment was carried out with the radium and its lead protection placed back in the original position. One sheet of tinfoil, $.0196 \mathrm{~mm}$. in thickness, was inserted over the top of the ionization-chamber, and $8.14 \mathrm{mms}$. of aluminium were then placed over the tin. Readings were then taken of the conductivity in the chamber for the two deflexions. These readings are given in Table XVIII., and

\section{Table XVIII.}

Thickness of aluminium over the top of chamber $=8 \cdot 14 \mathrm{mms}$. Thickness of tin over the top of chamber $=\cdot 0196 \mathrm{~mm}$.

Aluminium above tin.

\begin{tabular}{|c|c||c|c|}
\hline \multicolumn{2}{|c|}{$\begin{array}{c}\beta \text { rays deflected towards } \\
\text { chamber. }\end{array}$} & $\begin{array}{c}\beta \text { rays deflected away from } \\
\text { chamber. }\end{array}$ \\
\hline $\begin{array}{c}\text { Current } \\
\text { through } \\
\text { magnet }\end{array}$ & $\begin{array}{c}\text { Saturation } \\
\text { Current. }\end{array}$ & $\begin{array}{c}\text { Current } \\
\text { through } \\
\text { magnet } \\
\text { (amperes). }\end{array}$ & $\begin{array}{c}\text { Saturation } \\
\text { Current. }\end{array}$ \\
\hline $0 \cdot 0$ & $16 \cdot 31$ & $0 \cdot 0$ & $16 \cdot 26$ \\
$2 \cdot 5$ & $16 \cdot 29$ & $2 \cdot 5$ & $16 \cdot 06$ \\
$4 \cdot 5$ & $16 \cdot 08$ & $4 \cdot 5$ & $15 \cdot 77$ \\
$6 \cdot 5$ & $15 \cdot 86$ & $6 \cdot 5$ & $15 \cdot 43$ \\
$10 \cdot 0$ & $15 \cdot 75$ & $10 \cdot 0$ & $15 \cdot 38$ \\
$15 \cdot 0$ & $15 \cdot 60$ & $15 \cdot 0$ & $14 \cdot 89$ \\
$23 \cdot 0$ & $15 \cdot 43$ & $22 \cdot 0$ & $14 \cdot 74$ \\
\hline
\end{tabular}


the curves $A$ and $A^{\prime}$ representing them are drawn in fig. 16 . These curves and the curves $\mathbf{E}$ and $\mathbf{E}^{\prime}$ drawn in fig. 13 are on the same scale. A comparison of the latter, which correspond. to a screen of $8.14 \mathrm{mms}$. of aluminium alone over the top of the chamber, with the curves $A$ and $A^{\prime}$ in fig. 16 , makes it clear that the insertion of the sheet of tinfoil beneath the aluminium screen brought the curves representing the two deflexions more nearly into coincidence. The natural conclusion would be then, that for a greater thickness of tinfoil below the aluminium, the two curves representing the ionizations for the two deflexions would coincide. To test this conclusion, four sheets of tinfoil, or a thickness of $\cdot 0784 \mathrm{~mm}$., were placed above the opening of the chamber, and over this the $8.14 \mathrm{~mm}$. of aluminium. The conductivity in the chamber. was then measured for different magnetic fields. The results are given in Table XIX., and curve B illustrating them is.

\section{TABLE XIX.}

Thickness of aluminium over the top of chamber $=8 \cdot 14 \mathrm{mms}$. Thickness of tin over the top of chamber $=\cdot 0784 \mathrm{~mm}$.

Aluminium above tin.

\begin{tabular}{|c|c|c|c|}
\hline \multicolumn{2}{|c|}{$\begin{array}{c}\beta \text { rays deflected towards } \\
\text { chamber. }\end{array}$} & \multicolumn{2}{|c|}{$\begin{array}{c}\boldsymbol{\beta} \text { rays deflected away from } \\
\text { chamber. }\end{array}$} \\
\hline $\begin{array}{c}\text { Current } \\
\text { through } \\
\text { magnet } \\
\text { (amperes). }\end{array}$ & $\begin{array}{l}\text { Saturation } \\
\text { Current. }\end{array}$ & $\begin{array}{c}\text { Current } \\
\text { through } \\
\text { magnet } \\
\text { (amperes). }\end{array}$ & $\begin{array}{l}\text { Saturation } \\
\text { Current. }\end{array}$ \\
\hline $\begin{array}{c}0 \cdot 0 \\
2 \cdot 5 \\
4 \cdot 35 \\
6 \cdot 5 \\
10 \cdot 0 \\
15 \cdot 0 \\
18 \cdot 0\end{array}$ & $\begin{array}{l}16 \cdot 00 \\
16 \cdot 04 \\
15 \cdot 66 \\
15 \cdot 66 \\
15 \cdot 44 \\
15 \cdot 35 \\
15 \cdot 19\end{array}$ & $\begin{array}{r}0 \cdot 1) \\
4 \cdot 5 \\
10 \cdot 0 \\
15 \cdot 0 \\
22 \cdot 0\end{array}$ & $\begin{array}{l}16 \cdot 10 \\
15 \cdot 69 \\
15 \cdot 56 \\
15 \cdot 39 \\
16 \cdot 17\end{array}$ \\
\hline
\end{tabular}

shown in fig. 16. The numbers in the table and the curve both show that with a screen made up in this way the conductivities in the chamber were identical for magnetic fields of equal intensity in either direction. This experiment showed clearly that the effect under consideration was due to a peculiarity in the secondary radiation emitted by the aluminium.

(4) In the fourth experiment the radium protected by the lead cylinder was placed vertically above the ionizationchamber and also above the poles of the magnet in such 
a way that the pencils of rays from the radium were directed straight into the ionizing-chamber. The saturation currents for magnetic fields in both directions, when the $8.14 \mathrm{mms}$. of aluminium alone covered the chamber, were then measured. From the values of these currents, which are recorded in Table XX., it will be seen that the ionization corresponding

\section{TABLe XX.}

Thickness of aluminium over the top of chamber $=8 \cdot 14 \mathrm{mms}$. Radium vertically above chamber.

\begin{tabular}{|c|c|c|c|}
\hline \multicolumn{2}{|c|}{$\begin{array}{l}\beta \text { rays deflected towards } \\
\text { chamber. }\end{array}$} & \multicolumn{2}{|c|}{$\begin{array}{c}\beta \text { rays deflected away from } \\
\text { chamber. }\end{array}$} \\
\hline $\begin{array}{c}\text { Current } \\
\text { through } \\
\text { magnet } \\
\text { (amperes). }\end{array}$ & $\begin{array}{l}\text { Saturation } \\
\text { Current. }\end{array}$ & $\begin{array}{c}\text { Current } \\
\text { through } \\
\text { magnet } \\
\text { (amperes). }\end{array}$ & $\begin{array}{l}\text { Saturation } \\
\text { Current. }\end{array}$ \\
\hline $\begin{array}{r}0.0 \\
25 \\
4 \cdot 3 \\
6.4 \\
100 \\
150 \\
22.5\end{array}$ & $\begin{array}{l}15.69 \\
15.31 \\
15.13 \\
14.97 \\
14.81 \\
14.89 \\
14.72\end{array}$ & $\begin{array}{r}0 \cdot 0 \\
3 \cdot 0 \\
4.5 \\
6 \cdot 3 \\
10 \cdot 0 \\
15 \cdot 0 \\
22 \cdot 5\end{array}$ & $\begin{array}{l}15 \cdot 37 \\
15 \cdot 31 \\
15 \cdot 23 \\
14 \cdot 78 \\
14 \cdot 66 \\
14 \cdot 82 \\
14 \cdot 74\end{array}$ \\
\hline
\end{tabular}

to any selected field-intensity was the same for both directions of the field. Since the disposition of the apparatus in this experiment was symmetrical, it follows that the effect noted with the previous arrangement was not only connected with some special property of the secondary radiation excited in the aluminium by the $\gamma$ rays, but it also was due evidently to a non-symmetrical configuration of these secondary rays in the ionizing chamber.

The following is offered as an explanation of the foregoing experiments :-

In fig. 17 (p. 150), A represents the ionization-chamber, B the electrode, $\mathrm{CD}$ the aluminium screen, and $\mathrm{R}$ the position of the radium in the non-symmetrical arrangement. From a consideration of the figure, it is evident that the line RA, which is the axis of a pencil of $y$ rays entering the chamber, will mark the line of greatest intensity of these rays ; since for all other rays the metal path traversed is longer, and consequently the absorption is greater. It follows then that $\mathrm{RA}$ will also represent the direction of the axis of the pencil of secondary rays of greatest intensity issuing from the back of 
the aluminium plate. If then the magnetic field were applied in such a direction as to deflect the primary $\beta$ rays down into the chamber, this field, since the chamber was so situated as to be affected by the field, would deflect the secondary rays

Fig. 17.

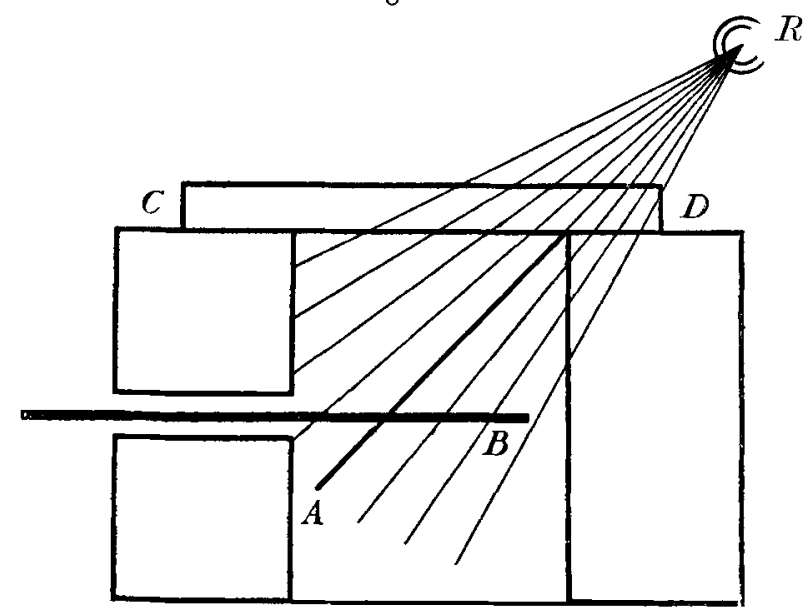

issuing from the back of the aluminium screen in the same direction. With the field in the opposite sense, the primary $\beta$ rays would be deflected upwards and away from the chamber, and the secondary rays in the chamber would also be turned by this field in a similar way, i.e., with one direction of the field the axis of the pencil of secondary rays corresponding to RA would be turned anti-clockwise, while with the field reversed this pencil would undergo a clockwise deflexion. From the diagram shown in fig. 17 it can be seen that when the pencil of maximum intensity $R A$ is given a clockwise rotation, the air-path traversed by it will be lessened, and consequently the ionization produced by it reduced. On the other hand, with the anti-clockwise rotation the length of path traversed by this pencil will be increased; and hence one should not expect the magnitade of the decrease in ionization following the application of the field producing this deflexion to be as great as when the field applied caused the rays to be deflected in the opposite sense. It is evident, too, that the tertiary rays. excited on the walls of the chamber by the aluminium secondary rays would be greater in the case of the anti-clock wise rotation of the secondary rays than in experiments when the rotation of these rays was in the opposite direction. One naturally 
inquires why this effect did not appear in the experiments when tin and lead were used as coverings for the openings into the chamber, and also when a thickness of $0.0784 \mathrm{~mm}$. of tinfoil was placed below the aluminium cover. The probable explanation is that the transmitted secondary rays from tin and lead are not so effective ionizing agents or so good exciters of tertiary rays as the secondary rays from aluminium. The effect even in the case of aluminium is small, although quite noticeable; and it is probable, therefore, with the weaker secondary rays from the tin and lead, that the effect would be very much less and consequently masked by the other influences present.

The experiments which have just been described are also interesting for the light which they throw on the nature of the transmitted secondary radiation excited in the metals aluminium, tin, and lead by $\gamma$ rays. According to the argument which has been presented, it follows from Bragg's conclusions, since the serondary rays from aluminium are better ionizers than those from tin and lead, that the particles constituting these secondary rays must be endowed with smaller velocities than those constituting the secondary radiation from the other two metals. 'The transmitted $\gamma$ excited secondary rays from aluminium should therefore, from this point of view, be more easily absorbed than those emitted by tin and lead.

This conclusion regarding the character of the transmitted secondary radiation excited in aluminium by $\gamma$ rays is in accord with the conclusions of McClelland *, Starke $\dagger$, and others, who have found an exceptionally high coefficient of absorption for the reflected secondary rays excited by $\beta$ and $\gamma$ rays in this metal.

\section{A Comparison of the Secondary Radiations} EXCITED IN DIFFERENT Metals by $\beta$ RaYs.

Some conclusions of interest can also be drawn from the results of the experiments of the present investigation regarding the secondary rays excited in different metals by $\beta$ rays. For the purpose of making a comparison, the thicknesses of the limiting absorbing layers of the three metals studied with both reflected and transmitted rays are

* McClelland, Trans. Roy. Mublin Suc. viii. p. 169 (1905).

+ Starke, Le Radium, Feb. 1908. 
collected in Table XXI., and in fig. 18 curves are drawn with the thicknesses of the absorbing layers as abscissæ and the

TABLE XXI.

\begin{tabular}{|c|c|c|c|}
\hline & Lead. & Tin. & Aluminium. \\
\hline $\left.\begin{array}{c}\text { Thickness required to } \\
\text { absorb } \beta \text { aud } \beta \text { se- } \\
\text { condary radiation. }\end{array}\right\}$ & $\underset{09}{\mathrm{~mm}}$ & $\underset{2 \cdot 5}{\operatorname{mm}}$ & $\underset{70}{\mathrm{~mm}}$ \\
\hline $\begin{array}{c}\text { Thickness giving maxi- } \\
\text { mum reflected se- } \\
\text { condary radiation } \\
\text { due to } \beta \text { rays.......... }\end{array}$ & 0.16 & 0.24 & 0.4 \\
\hline 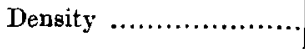 & $11 \cdot 3$ & $7 \cdot 3$ & $2 \cdot 6$ \\
\hline
\end{tabular}

densities of the absorbing substances as ordinates. The curve $A$ is plotted from the results of the transmitted radiation experiment, while the curve $B$ corresponds to the measurements on the reflected rays. It will be noticed that the scale of abscissæ used for the latter curve is only one-tenth that adopted in laying out the former. From the results in the table and from the form of the curve, it will be seen that the thicknesses of the absurbing material required to stop the $\beta$ and $\beta$ secondary rays were not directly proportional to the densities, but that as the densities decreased it required a greater thickness to stop the rays than should have been expected from density considerations alone.

It is highly probable that the maximum depth from which the secondary rays come on the front side of a metal plate when primary $\beta$ rays impinge on it represents the thickness that the secondary rays excited by the primary ones will penetrate in that metal. Now if the secondary rays excited by the primary in the three metals are all of the same penetrability, one should expect, on the assumption that they are $\beta$ rays, that numbers representing the maximum penetrability found for these secondary rays would follow the same absorption-law with reference to the density that the numbers representing the maximum penetrabilities of the primary radiation followed. In other words, the two curves $A$ and $B$ should be similar in form if the secondary rays excited in the three metals possess the same penetrability. But it is clear from the manner in which the two curves 
intersect in the figure, that they do not typify the same absorption law. It will be seen from the curve $B$ that the maximum penetrabilities of the secondary $\beta$ rays, as determined by the reflexion experiments, approach very closely to a linear relation which exhibits in a striking manner the important result that secondary rays excited in plates of different metals when $\beta$ rays are allowed to fall on them are the more penetrative the greater the density of the metal of which the reflector is made.

\section{Summary of Results.}

(1) The $\beta$ radiation from radium bromide, which includes the $\beta$ radiations from all the radium products in the equilibrium state, will not produce any ionization on the far side of a plate of aluminium $7 \mathrm{mms}$. in thickness, of a plate of tin $2.5 \mathrm{mms}$. in thickness, or of a plate of lead $\cdot 9 \mathrm{~mm}$. in thickness.

(2) The maximum secondary radiation emitted from the front side of plates of the metals aluminium, tin, and lead, when bombarded by $\beta$ rays, are given by the following thicknesses :-

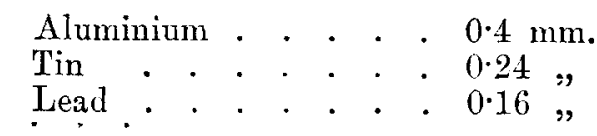

(3) The transmitted secondary radiations excited by $\gamma$ rays in lead and tin are more penetrating than the transmitted secondary radiation excited in aluminium by the same rays.

(4) When $\beta$ rays are allowed to fall in turn on reflectors of different metals, it is found that the greater the density of the metal from which the reflector is made the greater is the penetrability of the reflected secondary rays excited by the $\beta$ radiation.

(5) From the experiments on the transmission of $\beta$ rays through sheets of aluminium-foil, it has been shown that when very thin sheets of the metal are used the ionization at first contributed by the transmitted secondary radiation excited by the $\beta$ rays is greater than that lost through absorption of the primary rays.

In conclusion, I wish to express my best thanks to Prof. McLennan, at whose suggestion the investigation was undertaken, for his help and advice and unfailing kindness throughout the course of the research. 


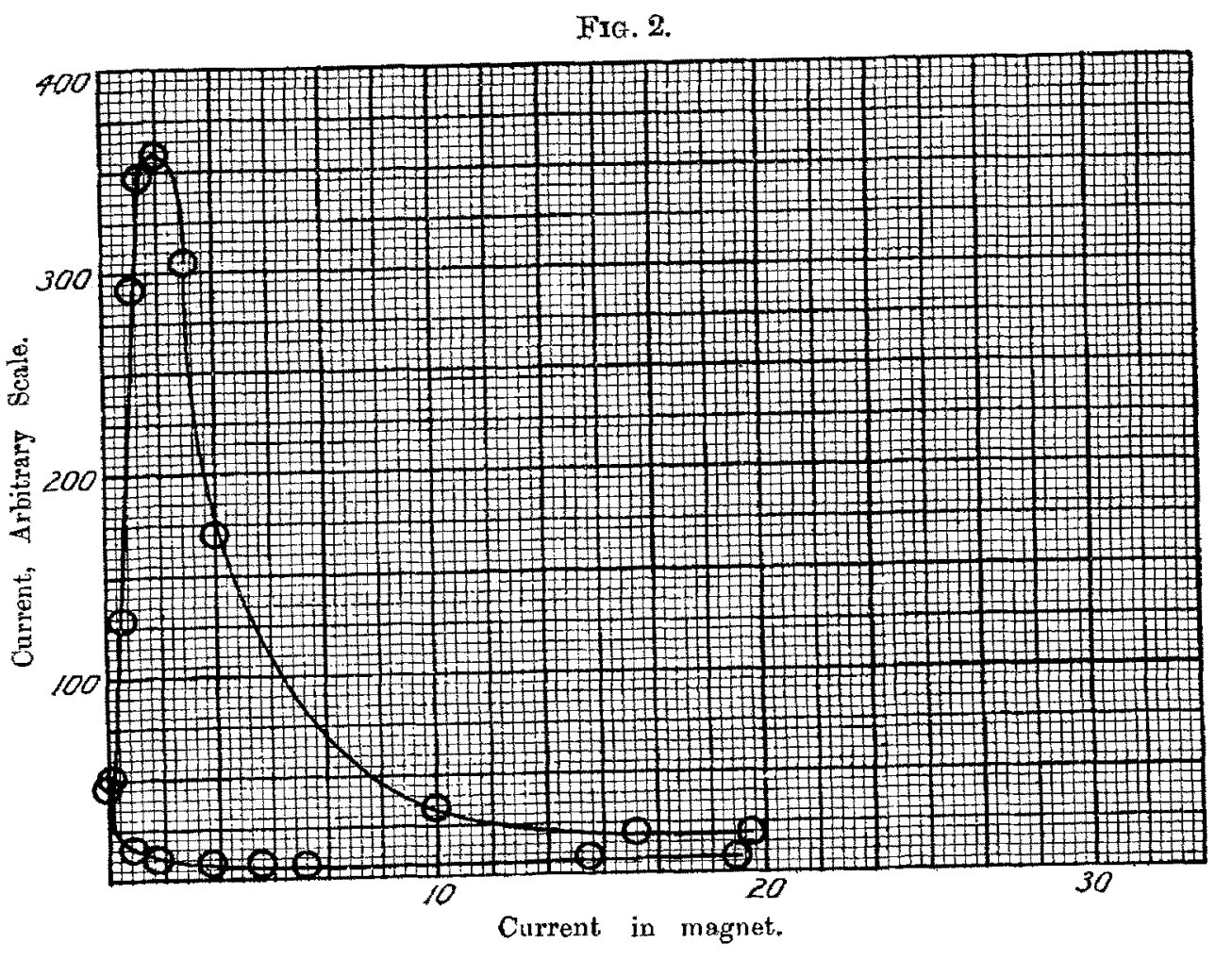

FrG. 3.

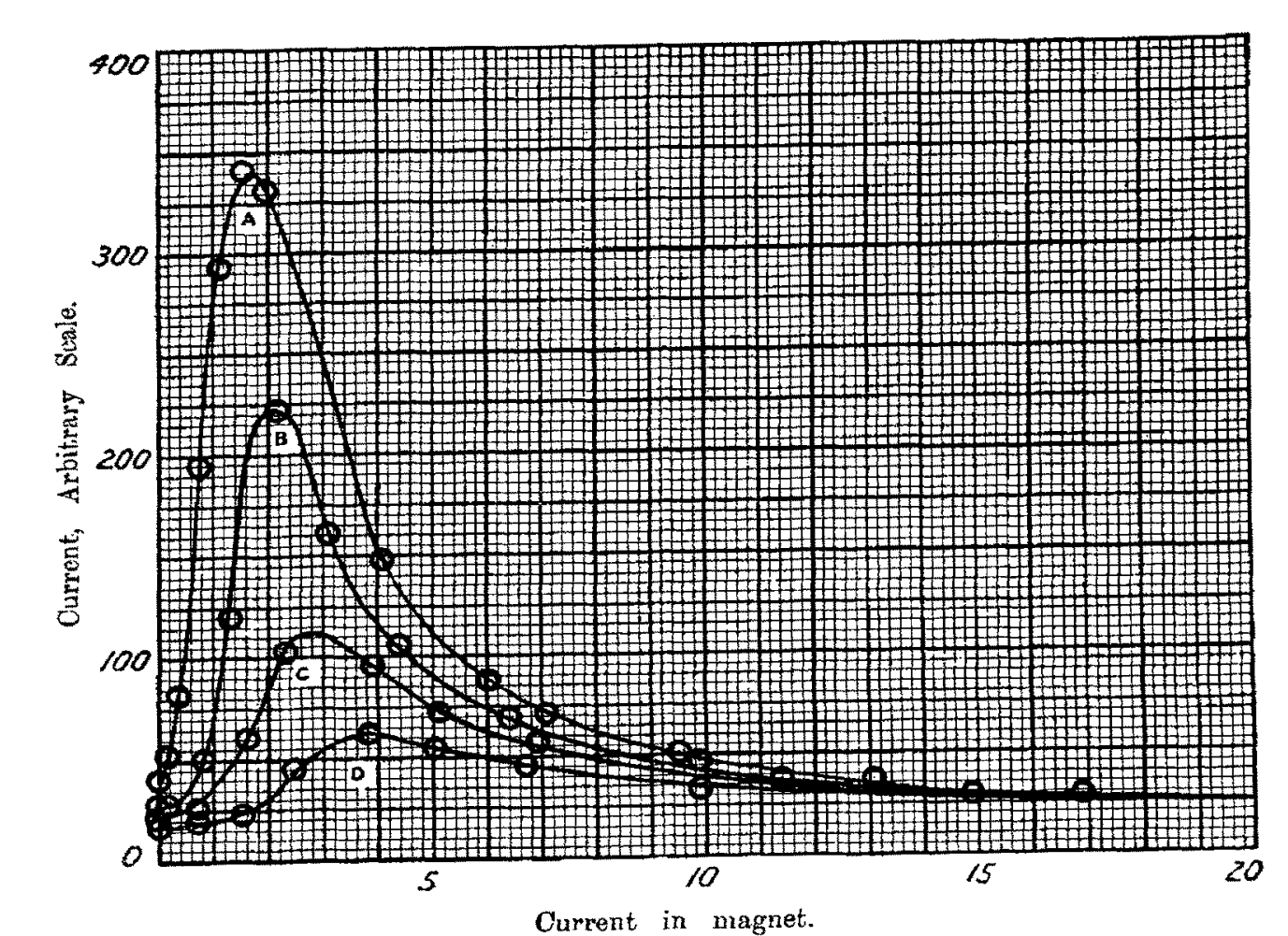

$$
\text { Current in magnet. }
$$

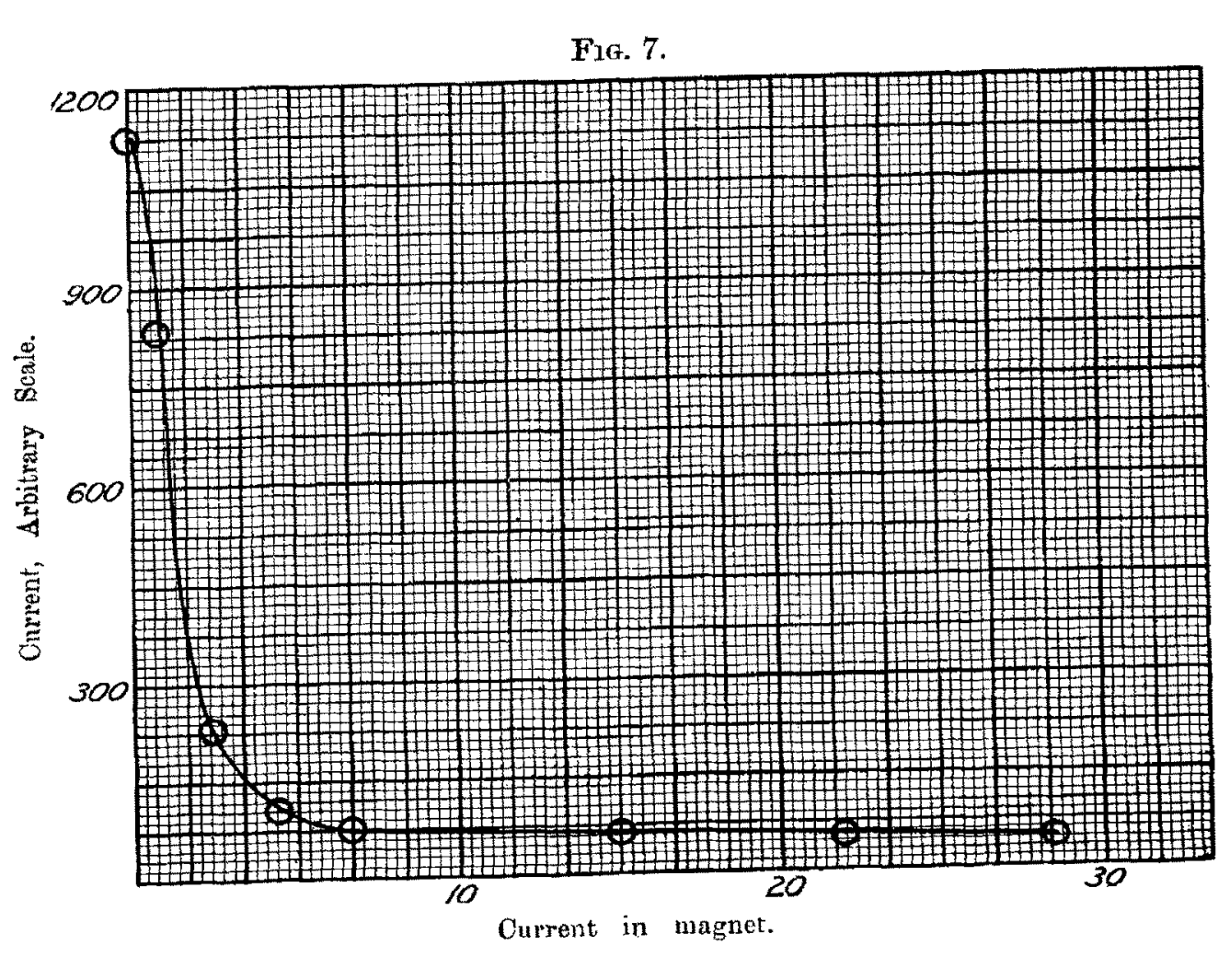

Fre 11.

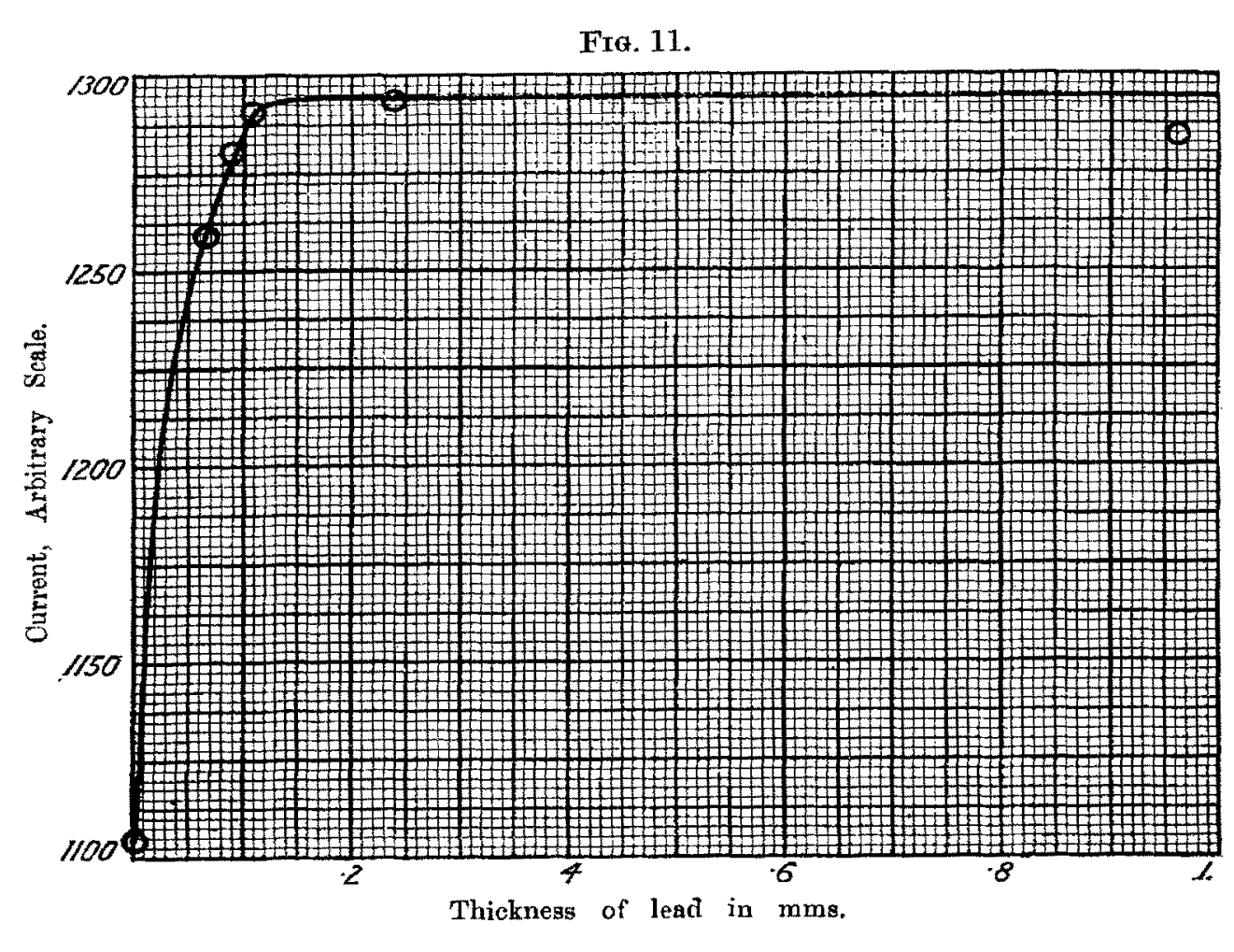
$\begin{array}{ccc}25 & 5 \\ \text { Thickness of lead in mws. }\end{array}$

Fra. 14.

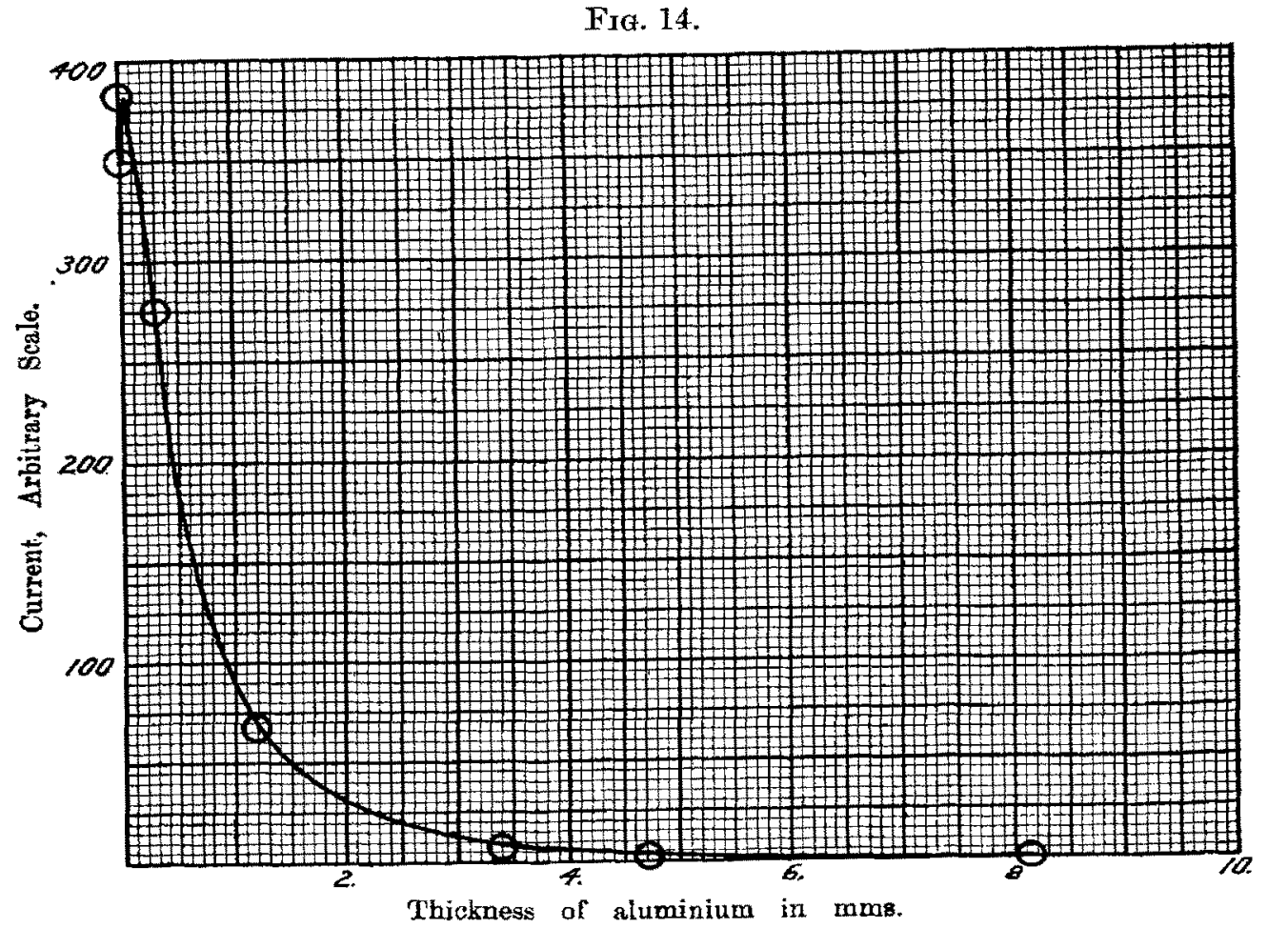

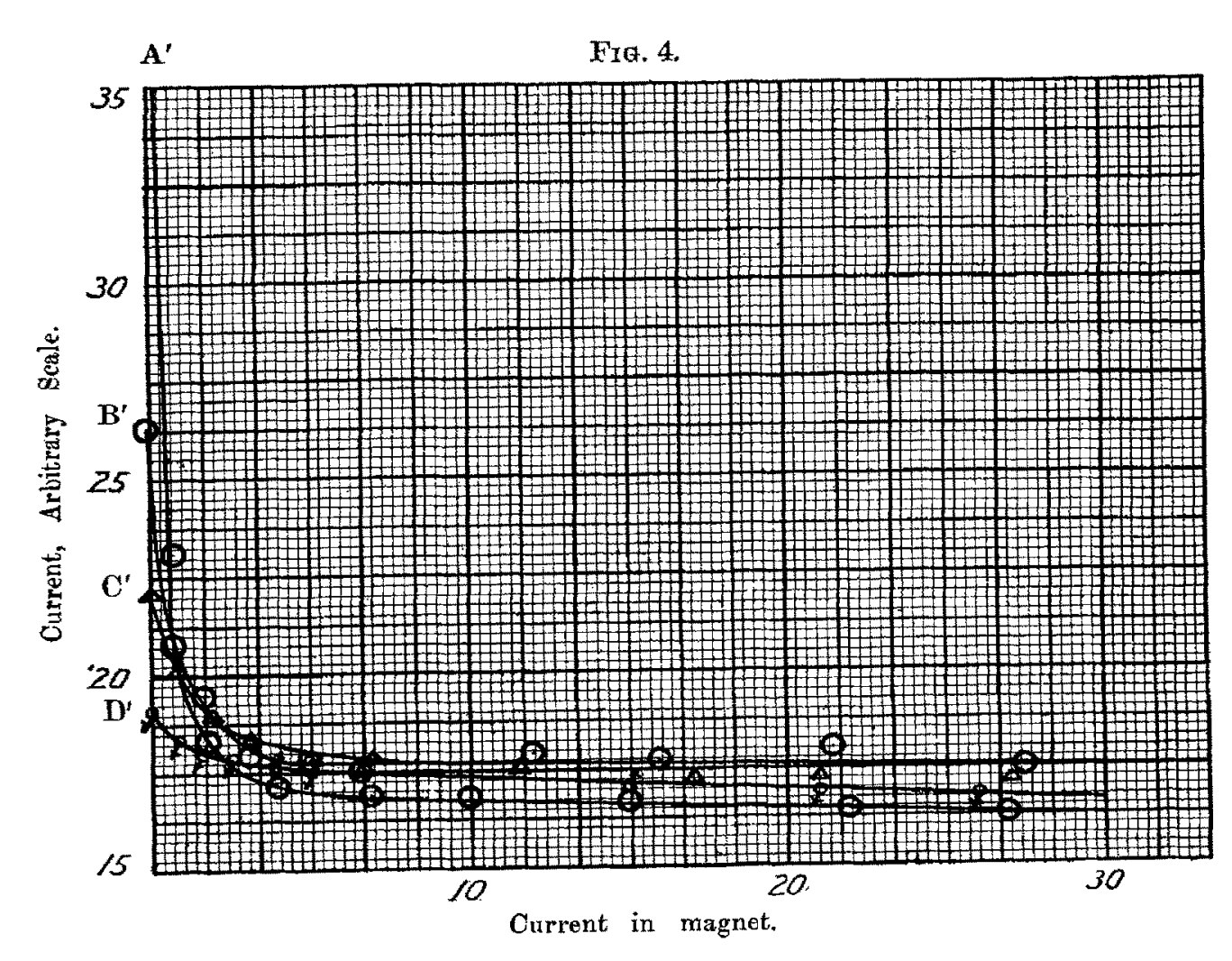

FIo.

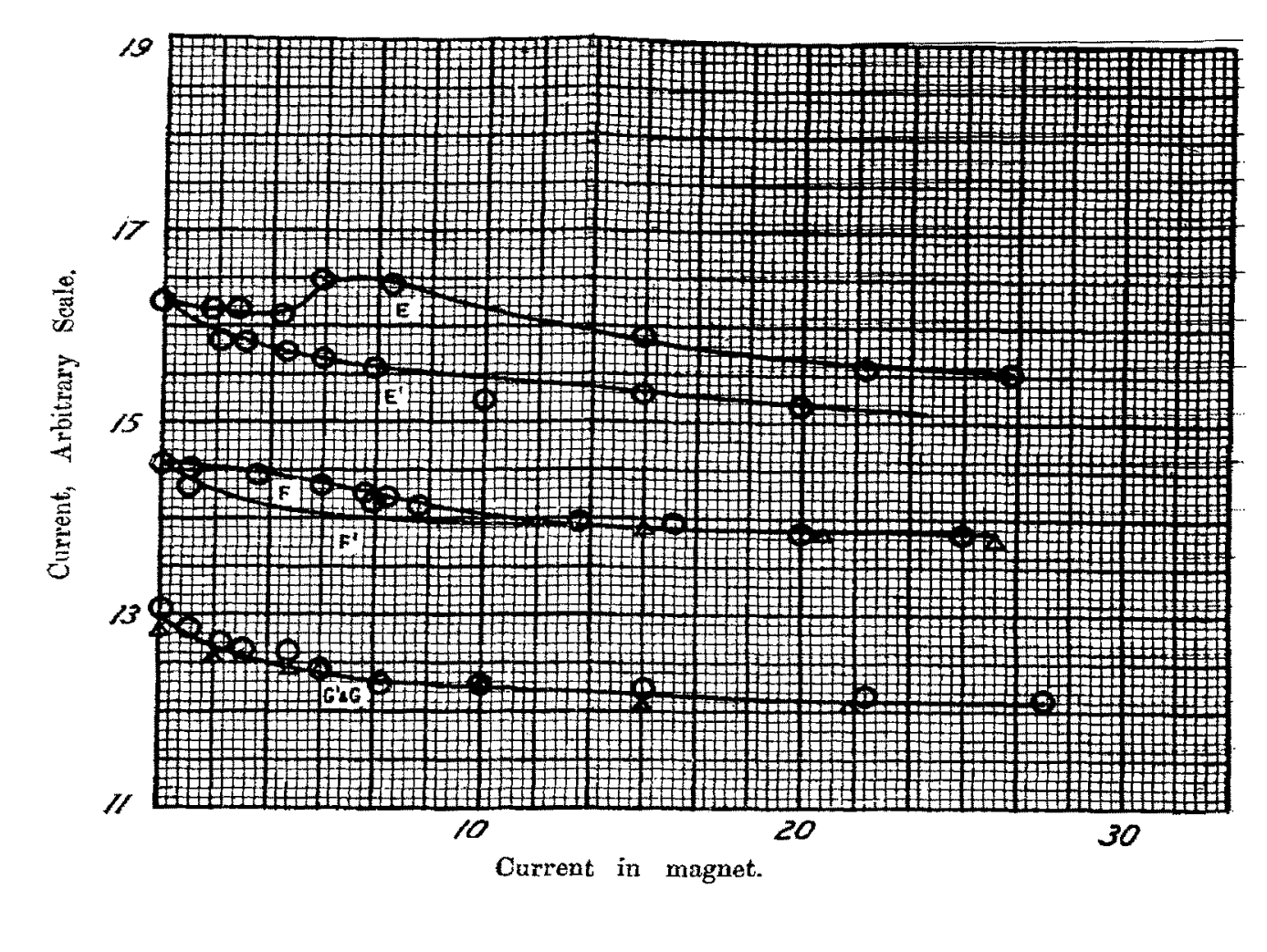

Fra. 9.
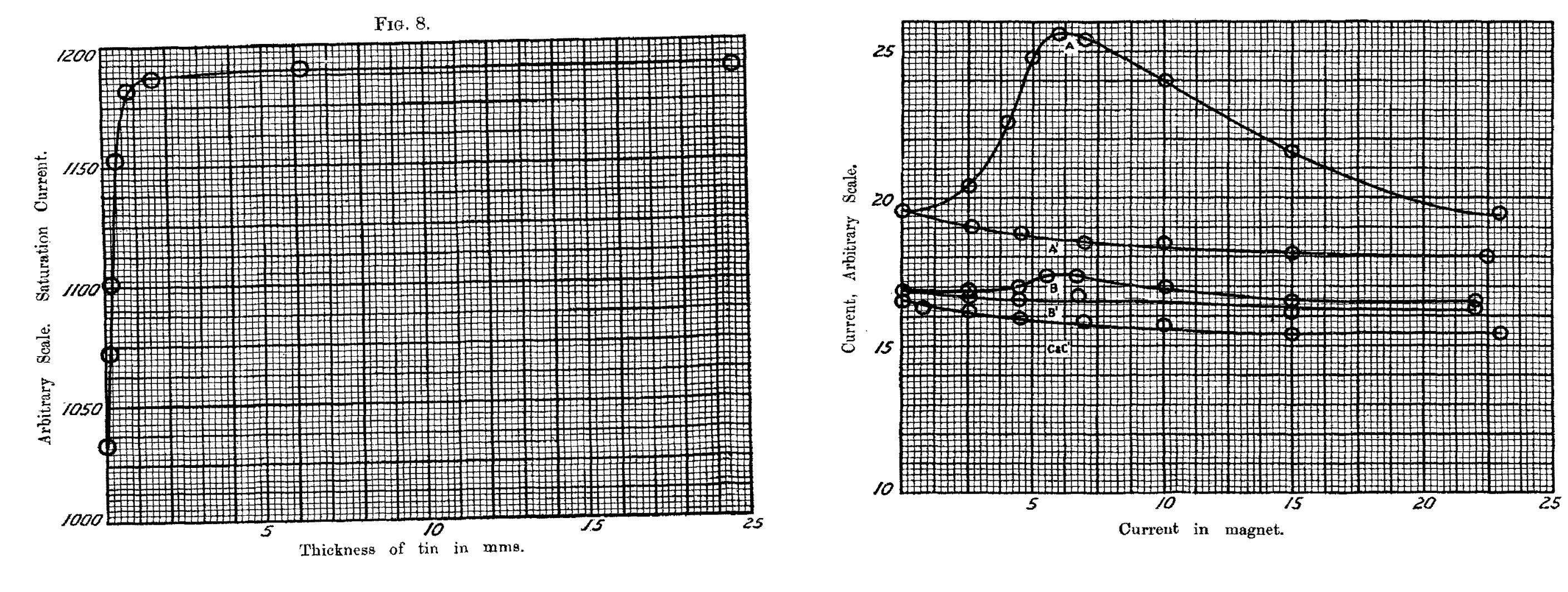

Fra. 12.

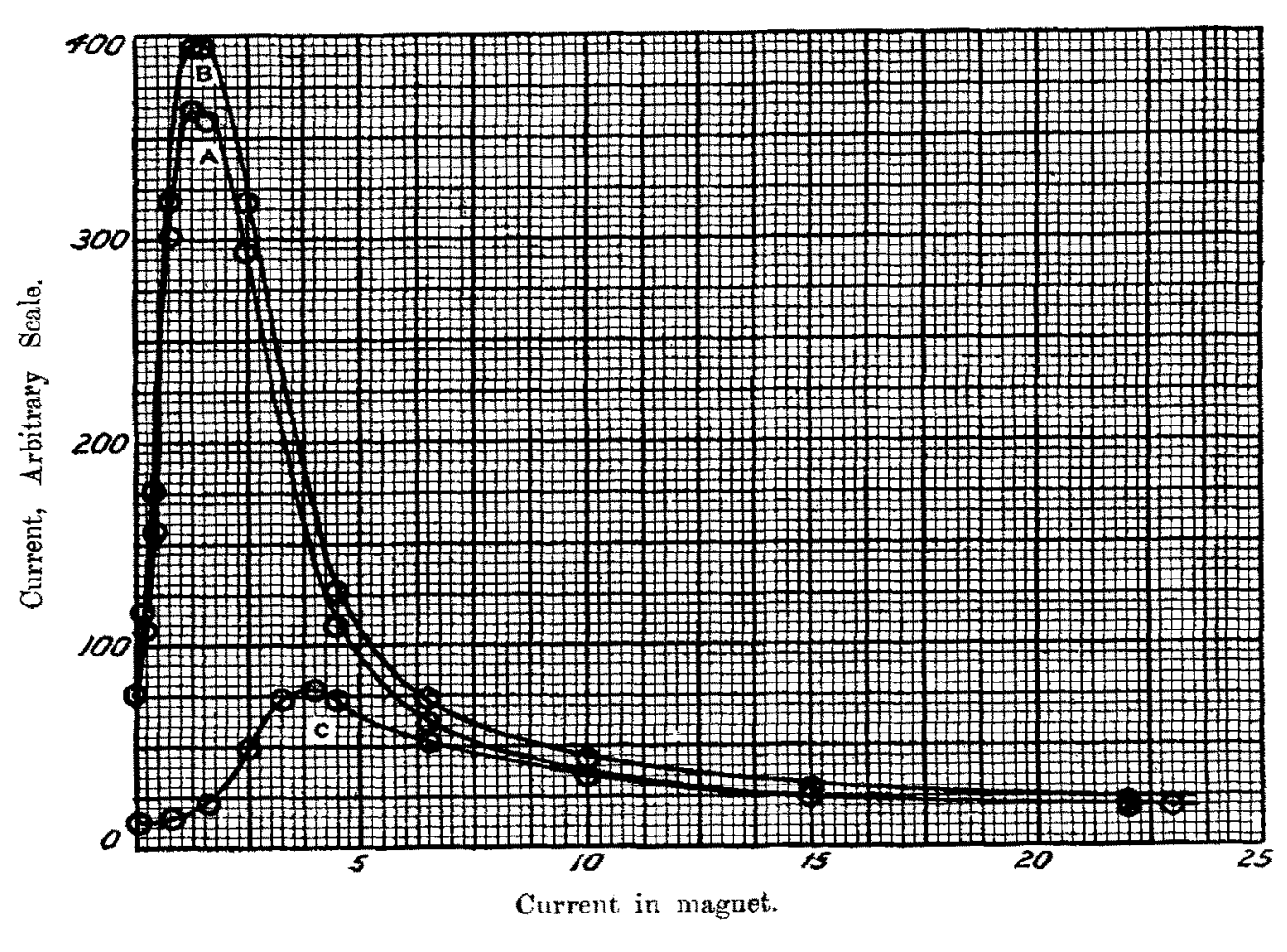

FIG. 16.

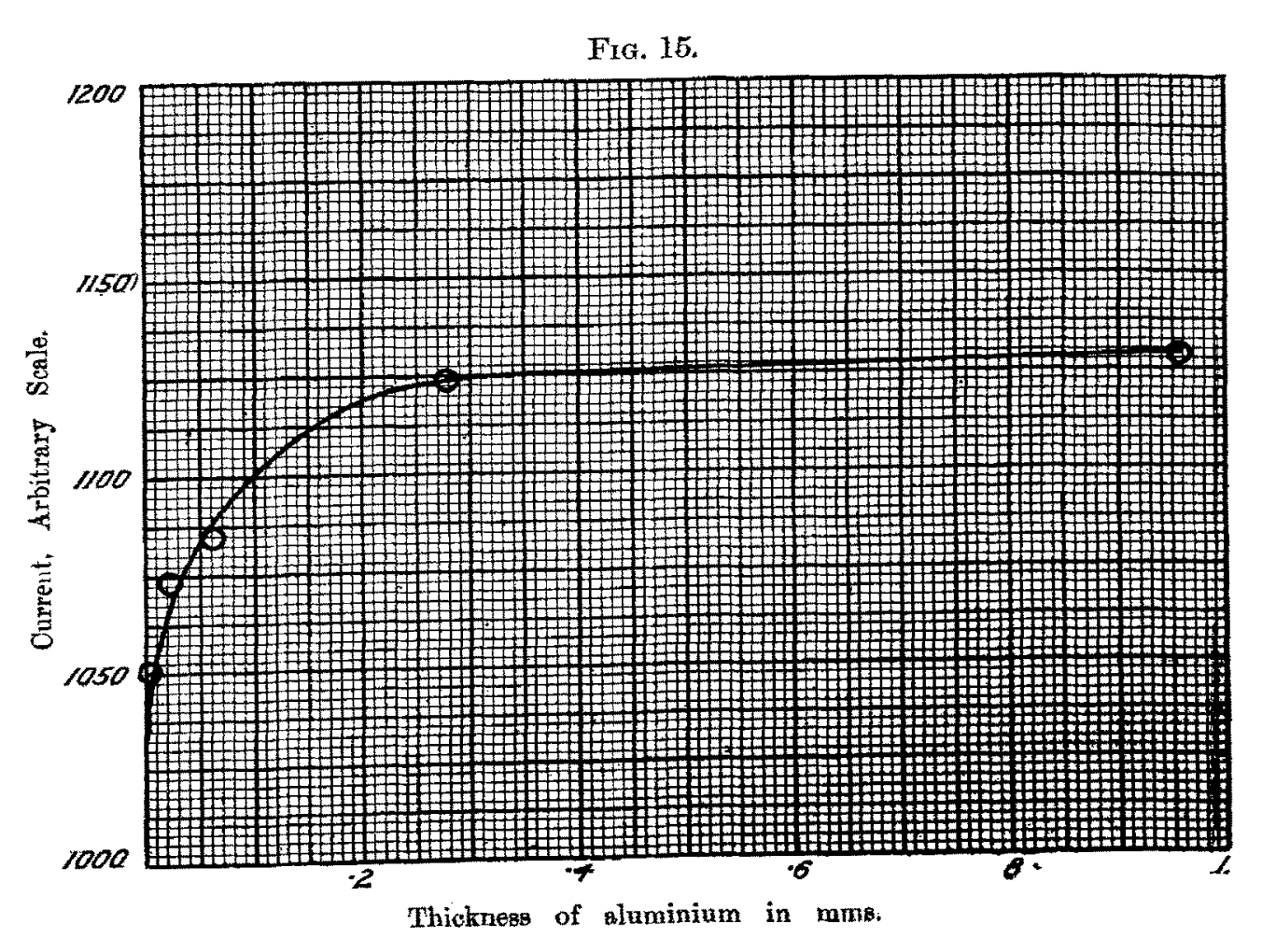

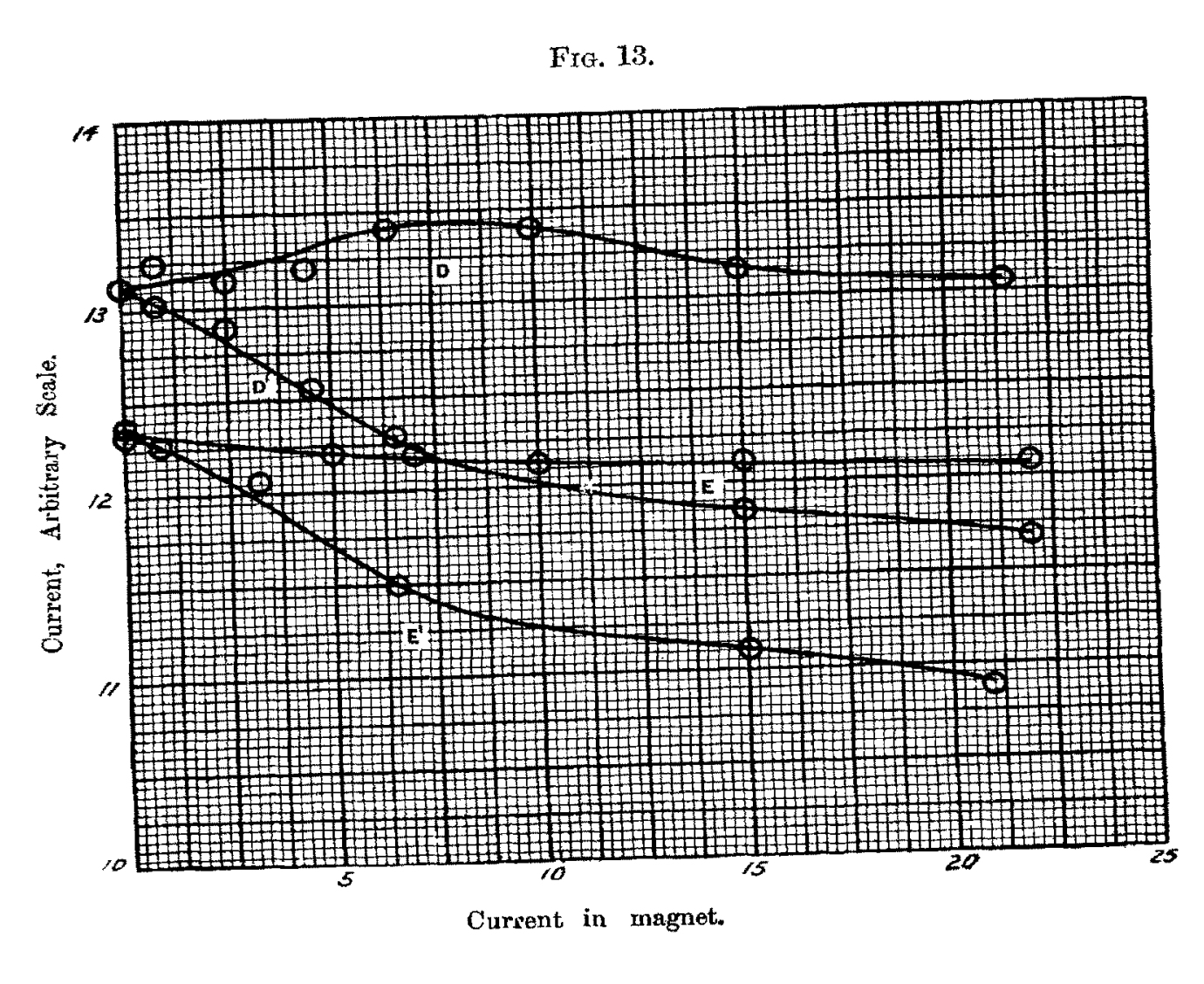

Fra. 18

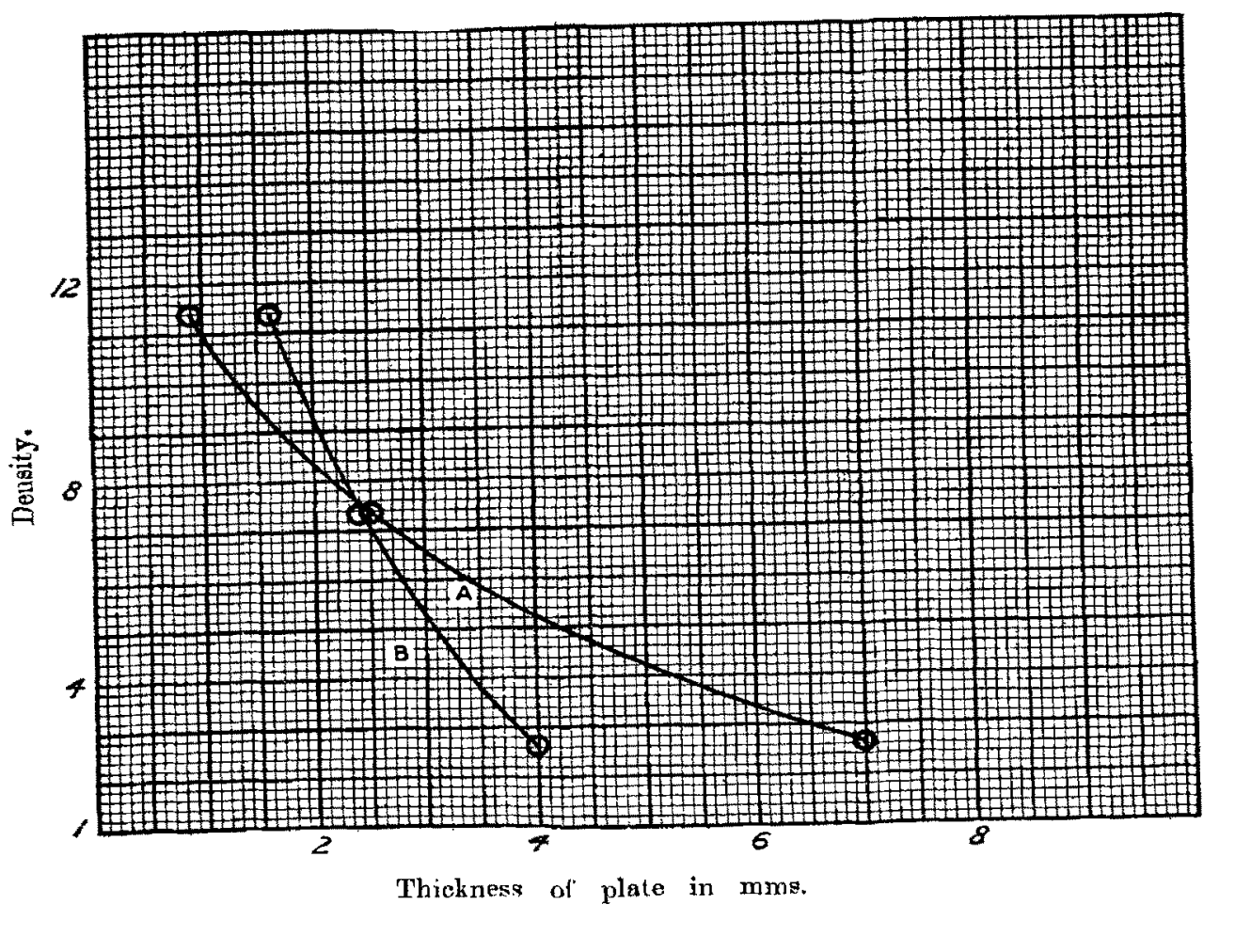

